\title{
Processing Complex Sentences: A Cross-linguistic Study
}

\author{
Elizabeth Bates \\ University of California San Diego, La Jolla, CA, USA \\ Antonella Devescovi and Simona D'Amico \\ University di Roma 'La Sapienza', Rome, Italy
}

The Competition Model is an interactive-activation framework for the study of sentence processing that is designed to handle quantitative as well as qualitative variations in performance across natural languages. Previous studies within this framework have shown that adult listeners base their interpretation of simple sentences on the most valid and reliable cues in their language (e.g. more use of word order in English and more use of subjectverb agreement in Italian). Critics have argued that such effects may reflect heuristics that are only applied to simple sentences. The present study shows that these cross-linguistic differences are maintained when participants are asked to interpret complex sentences with an embedded relative clause. A comparison of "off-line" (untimed) and "on-line" (timed) versions of the same experiments shows that these effects hold up under time pressure. The on-line versions also provide new information about cross-linguistic differences in timing and demands on processing. In particular, the processing costs associated with centre embedding and non-canonical order are greater in English, which may be the price that English listeners have to pay for heavy reliance on word order information.

\section{INTRODUCTION}

The Competition Model is an interactive-activation framework for the study of sentence processing that is designed to handle quantitative as well as qualitative variations in performance across natural languages

Requests for reprints should be addressed to Elizabeth Bates, Center for Research in Language, 0526, University of California San Diego, La Jolla, CA 92093-0526. E-mail: bates@crl.ucsd.edu

This research was supported by NIDCD grant PHS DC00216 ("Cross-linguistic studies in aphasia") to E.B.. 
(MacWhinney \& Bates, 1989). The term "competition" reflects a central assumption of the model: That different sources of information (i.e. "cues") converge, compete and/or conspire to determine the outcome of sentence processing, with different outcomes depending on the relative strength of cues from one language to another. For example, the model is designed to capture the fact that two languages with the same basic word order (e.g. subject-verb-object, or SVO) can differ markedly in the extent to which listeners rely on word order information to assign semantic roles in sentence comprehension, compared with other sources of information like subject-verb agreement.

In a long series of sentence comprehension studies, researchers working within the Competition Model have shown that listeners rely on the most valid (i.e. frequent and reliable) sources of information in their language. MacWhinney and Bates (1989) refer to this effect as "cue validity", a term borrowed from Brunswik (1956). English is a language in which word order is high in cue validity: Constituent order is rigidly preserved across sentence types, and correlates highly with semantic roles (i.e. "who did what to whom"). Italian is in the same typological category (SVO, without case marking on nouns), but word order is low in cue validity; that is, because extensive variation of word order is permitted for pragmatic purposes, the correlation between word order and semantic roles is relatively low. Studies of sentence comprehension in these two languages have shown that English listeners rely primarily on word order to decide "who did the action", making little use of subject-verb agreement or semantic contrasts. Italian listeners are heavily influenced by subject-verb agreement and semantic contrasts, but they pay little attention to word order. The same paradigm has now been used in more than a dozen languages (English, Italian, Spanish, French, German, Dutch, SerboCroatian, Hungarian, Japanese, Chinese, Warlpiri, Hebrew, Arabic, Greek; for summaries, see Li, Bates, \& MacWhinney, 1993; MacWhinney \& Bates, 1989). It is clear from these studies that many different profiles or hierarchies of cue utilization are possible (e.g. word order $>$ agreement $>$ semantics in English; case $>$ agreement $>$ semantics $>$ word order in SerboCroatian; passive marking $>$ semantics $>$ word order $>$ topic marking in Chinese). For any given language, the most valid cues also tend to be the first ones used by children (Devescovi et al., 1998; Kail, 1989), the most prone to transfer during second-language learning (Hernandez, Bates, \& Avila, 1994; Kilborn \& Ito, 1989; Liu, Bates, \& Li, 1992), and the most resistant to loss following focal brain injury (Bates, Wulfeck, \& MacWhinney, 1991).

In most of these studies, listeners are asked to "choose the one who did the action" in response to simple sentences or sentence-like strings consisting of a transitive verb and two concrete animate or inanimate 
nouns. These stimuli are constructed to represent orthogonal combinations of cue types, including word order, semantic reversibility, subject-verb agreement, case marking, contrastive stress and topic marking. Because factorial designs are used, the stimuli represent all possible competing and converging combinations of cues to sentence meaning. Hence it is possible to evaluate the relative strength of comparable linguistic forms from one language to another (Massaro, 1987). On the other hand, this factorial approach also means that listeners are sometimes faced with a combination of grammatical and semi-grammatical stimuli. Some typical examples from English would include the following:

1. The horse is kicking the cow. (NVN, Animate-Animate, neutral agreement)

2. The dog the cat is chasing. (NNV, Animate-Animate, neutral agreement)

3. Is kissing the boy the girl. (VNN, Animate-Animate, neutral agreement)

4. The ball is pushing the elephant. (NVN, Inanimate-Animate, neutral agreement)

5. The tiger are chasing the bears. (NVN, Animate-Animate, 2nd noun agrees)

6. The rocks is hitting the pig. (NVN, Inanimate-Animate, 2nd noun agrees)

7. Is hitting the rabbit the pencils. (VNN, Animate-Inanimate, 1st noun agrees)

8. The boy are pushing the blocks. (NVN, Animate-Inanimate, 2nd noun agrees)

To illustrate, consider the following findings for English and Italian on sentences like these and their Italian equivalents, replicated in several different experiments (Bates et al., 1982, 1984, 1987;; Devescovi et al., 1998; Hernandez et al., 1994; Liu et al., 1992; MacWhinney, Bates, \& Kliegl, 1984).

Starting with sentence (1), any theory of sentence processing in English or Italian would necessarily predict a SVO interpretation, and that is exactly what we find. However, our studies have also shown that use of SVO is quantitatively greater in English than in Italian on semantically and morphologically reversible items of this kind (averaging 10\% more choice of the first noun in English from one experiment to another). To explain this outcome, one needs to know something about the relative strength of cues like SVO in English versus Italian-a kind of information that is left out of many parsing and sentence interpretation theories. 
Languages can also vary in the way that listeners respond to noncanonical word orders like the NNV and VNN structures in sentences (2) and (3). In our previous studies using stimuli of this kind, we have shown that English adults are much more likely to choose "the cat" in sentence (2) and "the girl" in sentence (3), which are OSV and VOS interpretations that do not correspond to any single grammatical structure in this language. However, this result for English can be explained if we assume that listeners make use of the partial overlap between semi-grammatical stimuli and well-formed phrase structure types that do exist in the language. For example, it is true that subjects are overwhelmingly more likely to precede the verb in canonical SVO sentences, in relative clause constructions like "The boy that the girl kicked", and in left-dislocated structures that are permitted in informal speech within some dialects (e.g. "Now this one I like!'). The conjoint effects of these models could explain the OSV bias in English. Similarly, it is also true that objects are overwhelmingly more likely to follow the verb in canonical SVO sentences, in imperative constructions (e.g. "Hit the ball, John!'), and in right-dislocated "afterthought" structures that are occasionally observed in informal discourse (e.g. "Makes a mean apple pie, old Gertrude does"). These structures could explain the VOS bias that English listeners use to interpret VNN stimuli. In contrast with the VOS and OSV patterns observed in English, Italian listeners are close to the random $50 \%$ baseline in their interpretations of sentences like (2) and (3), presumably because OSV, SOV, VOS and VSO are all permitted in informal Italian discourse under some pragmatic and/or morphological conditions (Benincà, 1993; Simone, 1993). Across several experiments, Italians tend to show a slight bias towards SOV and VOS, but these trends are not always reliable.

In sentences like (4), most English listeners choose "the ball" as the actor, which means that SVO word order dominates over semantic contrasts in this language. In addition, English listeners usually choose "the tiger" as the actor in sentence (5), which means that SVO word order also wins in a competition against subject-verb agreement. The use of word order is so strong in English that listeners usually choose "the rocks" in sentence (6), where SVO word order must compete against the combined forces of animacy and agreement. Indeed, English listeners even trust their non-canonical OSV and VOS strategies more than they trust semantic or morphological information, evidenced in the fact that "the pencils" is chosen more often as the actor in sentences like (7), where VOS must compete against animacy and agreement. In contrast, Italians show dramatically different patterns of sentence interpretation with equivalent stimuli. On sentences like (4), Italians typically choose "the elephant" as the actor, which means that animacy wins in a competition with SVO word order. This cross-linguistic difference is even more dramatic on items like 
(5), where Italians are overwhelmingly more likely to choose "the bears" as the actor, suggesting that subject-verb agreement is far more important than SVO word order. Not surprisingly, the combined forces of animacy and agreement defeat word order handily in items like (6) and (7) for Italian listeners. Finally, on items like (8), where animacy and word order compete against agreement, English listeners continue to follow their SVO bias (choosing "the boy" as actor), but Italian listeners choose "the blocks" as actor, showing that subject-verb agreement is by far the most important cue within their language.

Although a large number of studies have used this method successfully, in many languages the method itself is still controversial (e.g. Caplan \& Hildebrandt, 1988; Gibson, 1992). Criticisms have focused on three issues: (1) Because listeners are asked to make explicit interpretations of agentpatient roles (i.e. "who did what to whom"), the task encourages use of conscious strategies. (2) The presence of ungrammatical stimuli could have a deleterious or unnatural effect on the processes listeners use to interpret any or all of the sentence stimuli. (3) Results may reflect "short-cuts" or heuristics that listeners use to interpret simple transitive sentences; the same processes may not hold when listeners are forced to parse and interpret complex sentence stimuli. The first two criticisms have been addressed in several previous studies, with arguments that we will summarise briefly here. The third criticism will be addressed in the present study, where we examine the profiles of cue utilisation that English and Italian speakers use to interpret complex sentence stimuli.

The first criticism can be decomposed into two problems: "strategies" and "consciousness". Our answer to the first problem is that strategies or heuristics are not necessarily a bad thing if the strategies that we elicit in our design generalise to those that are used in everyday life (Kimball, 1973). In this regard, we are comforted by the fact that the performance profiles displayed by native speakers in our cross-linguistic experiments correlate highly with independent measures of cue validity, and with performance across different laboratory tasks, including grammaticality judgement (Devescovi et al., 1997; Liu et al., 1992; Wulfeck, Bates, \& Capasso, 1991) and word monitoring (Kilborn, 1987). With regard to the supposed problem of consciousness, we note that perceptual psychophysics has made great strides through the use of methods that enlist the conscious cooperation of the perceiver. When we engage the subject's cooperation in deciding "who did the action" in our cross-linguistic studies, we are emloying a similar approach. Consciousness per se is not a problem; the real issue is whether the mix of conscious and unconscious processes tapped by a given technique generalises to real-time language use under natural conditions-which seems to be the case for the method that we have used. 
The second major criticism revolves around the mix of grammatical and semi-grammatical stimuli that are used in many of our experiments. To address this problem, we have carried out several studies in languages in which all the stimuli produced by a factorial design are grammatically acceptable (e.g. studies of Serbo-Croatian by Smith \& Mimica, 1984, and by Smith \& Bates, 1987). In those studies, we have found the same effects of cue validity, competition and convergence that emerge in factorial designs that use a mixture of grammatical and ungrammatical forms. This point was made explicitly by MacWhinney and Pléh (1988), who conducted two studies of sentence interpretation in Hungarian in which word order and animacy were pitted against the presence or absence of nominative/ accusative case marking. In one study, sentence stimuli without case marking were all ungrammatical; in another, the stimuli without case marking were all grammatical. The results were the same in both experiments. Findings like these have convinced us that our results and conclusions are valid, despite the presence of ungrammatical stimuli in a factorial design. Indeed, we believe that these stimuli can be just as revealing as the impossible figures and visual illusions that are so often used to study competing and converging principles in visual perception (Gregory, 1966).

The third criticism pertains to the limitations of a research program based entirely upon simple transitive sentences. Do the results that we have obtained for short sentence stimuli generalise to the parsing and interpretation of complex structures? Or are they "short-cuts" that are only used for simple sentence types (cf. Caplan \& Hildebrandt, 1988)? This criticism has not been addressed systematically in any of our comparative studies, although MacWhinney and Pléh (1988) have conducted a related study of relative clause interpretation within a single language, Hungarian. In that study, MacWhinney and Pléh took advantage of the fact that Hungarian permits a wide range of word order variations at the level of the matrix clause (SOV, SVO, OVS, etc.). As a result, they were able to test a range of competing theories of relative clause interpretation that are necessarily confounded within English. For example, Sheldon (1974) has proposed the Parallel Function Hypothesis to explain the fact that objectrelatives are more difficult to process than subject-relatives. Within a subject-relative (e.g. "The girl that pushed the boy opened the door"), the head noun "girl" plays the same role within both the matrix and the embedded clause; within an object-relative (e.g. "The girl that the boy pushed opened the door"'), the head noun is the subject in the matrix clause but it takes the object role within the embedded clause. Because of the opportunities offered by Hungarian, MacWhinney and Pléh were able to show that some of the strategies for parsing relative clauses that have been proposed in the English language literature are the by-product of two 
or more simple tendencies (e.g. "Take the speaker's point of view") that are confounded in English but separable in Hungarian.

The paper by MacWhinney and Pléh testifies to the value of crosslinguistic research to resolve issues that cannot be addressed within a single language (e.g. English). However, that within-language study does not provide a direct cross-language test of the cue validity hypothesis for complex sentence types. In the present study, we compare processing of transitive sentences with a relative clause in English and Italian, in order to determine whether the strong cross-linguistic contrasts that we have observed with simple sentence types are preserved when listeners have to parse more complex structures. We examine the strategies that are used to interpret the matrix clause when the first or second noun is modified by a relative; we also look at the strategies that English and Italian listeners use to interpret the relative clause itself.

In this regard, we need to underscore a paritcularly important and interesting characteristic of Italian: Word order can be varied for pragmatic purposes within both the matrix and the relative clause. Within the matrix clause, all possible orderings of subject, verb and object can be observed in Italian under some combination of pragmatic, semantic, morphological and/or prosodic conditions. These variations are more common in informal spoken language (Bazzanella, 1994; Duranti \& Ochs, 1979; Simone, 1990), but all of them have been observed in written discourse as well (Devescovi, 1986). Word order variation is not unusual in richly marked languages, including case-marked languages like Hungarian as well as languages like Italian that have no case inflections but do employ a rich set of agreement markers (e.g. subject-verb agreement, and agreement between objects and clitic pronouns). However, unlike Italian, many languages that permit word order variation within the matrix clause do not permit the same degree of freedom inside an embedded clause. Consider the following examples:

9a. The boy saw the woman that is hitting the man.

9b. Il ragazzo ha visto la donna che picchia l'uomo.

10a. The boy saw the woman that the man is hitting.

10b. Il ragazzo ha visto la donna che l'uomo picchia.

$(\mathrm{NVN}(\mathrm{VN}))$

$(\mathrm{NVN}(\mathrm{VN}))$

$(\mathrm{NVN}(\mathrm{NV}))$

$(\mathrm{NVN}(\mathrm{NV}))$

In English, these sentences are absolutely unambiguous: (9a) contains a subject-relative, in which the woman is the one who does the hitting (NVN(VO)), while (10a) contains an object-relative, in which the woman is hit $(\mathrm{NVN}(\mathrm{SV}))$. As we shall see, these are also the preferred readings in Italian. However, they are not the only possible readings. For morphologically ambiguous sentences like (9b) and (10b), two different readings are possible in Italian: In both sentences, the woman may be the one who 
does the hitting (so-called subject relatives, NVN(VO) or OV)) or the one who gets hit (so-called object relatives, NVN(VS or SV)). The existence of two alternative interpretations (albeit at different levels of probability) means that the reliability of word order information is low in Italian, in both the main clause and the relative clause. Under these conditions, the Competition Model predicts that Italians will prefer to make use of agreement information to interpret complex sentences, at every level of the sentence (i.e. main and/or subordinate clause). Conversely, we may expect English listeners to ignore agreement contrasts in favour of word information, in both the main clause and the relative clause. In other words, the same cross-linguistic differences that we have observed with simple sentence stimuli will replicate when subjects are required to interpret much more complex sentence types.

We will report results below for a series of studies in the visual modality. This is in contrast to most studies within the Competition Model, which have been carried out in the auditory modality. Hence, in addition to new explorations with complex sentences, we also need to build in a replication of our results for simple sentences. The decision to use visual stimuli was made to avoid any confounds that might result from known and unknown effects of sentence prosody on assignment of agent-patient roles (for examples, see MacWhinney et al., 1984). The first two studies were conducted "off-line", with subjects making their response to written stimuli in test booklets, at their leisure. The second two studies were conducted "on-line", with subjects instructed to make their decisions as quickly as possible to sentence stimuli presented one at a time on a computer terminal. The same sentence stimuli were used in both the offline and on-line studies.

\section{GENERAL METHODS}

Studies of relative clause processing are notoriously difficult to interpret and even more difficult to follow, because so many factors are involved. The factors of interest here include word order variations and agreement variations, in simple sentences (to ensure that our previous findings replicate in the visual modality) and within both the main clause and the relative clause in complex sentences; in the latter case, we also want to know if these factors vary depending on the position of the relative clause (i.e. whether it modifies the first or the second noun in the main clause). These factors would, if fully crossed, yield a $3 \times 2 \times 2 \times 3 \times 3 \times 2$ design for the complex sentences (with 216 cells) and a $3 \times 3$ design for simple sentences (with 9 cells), resulting in a minimum of 1125 trials (assuming no fewer than five sentences per cell). To get around this combinatorial explosion, we broke the full design into two separate experiments, one 
focusing on variations in word order in both the main and the relative clause (with agreement held constant), and another focusing on variations in agreement in both the main and the relative clause (with order in the main clause held constant, in its canonical form). Each of these experiments actually contains three sub-experiments that must be analysed separately: simple sentences (to replicate auditory effects in the visual modality), complex sentences in which participants must interpret the main clause, and complex sentences in which participants must interpret the relative clause. Hence the two larger experiments will require a total of six separate analyses of variance with language as a between-subjects factor. Because these experiments were conducted both off-line (untimed, in booklet form) and on-line (timed, with computer-controlled presentation), with separate subjects participating in the off-line and on-line versions, the study as a whole comprises 12 sub-experiments, which may result in a large number of effects. To reduce the likelihood of falsepositives, we have set the study-wide alpha level at $P<0.01$; the only effects discussed are those that reach this conservative level of significance. To reduce the reader's workload, statistical details for all significant main effects and interactions are reported in appendices.

Subjects. The subjects in all of our experiments are college students attending an urban university, and they are native speakers of English or Italian. The students who participated in Experiment 1 also participated in Experiment 2 (i.e. the off-line series), in counterbalanced order, in a single test session or in two separate sessions depending on their individual scheduling constraints. In contrast, Experiments 3 and 4 (i.e. the on-line series) each used a separate group of subjects.

Materials. To convert our usual "who did it?" task for use with complex sentences, we had to solve a methodological problem. If we want to ask our listeners to decide "who did it" in a complex sentence with three participants and two verbs, we have to decide which verb we want them to interpret on a given item, and we need an easy and straightforward way to convey that instruction. Our solution to this problem is called the "Who Dunnit?" task. All complex sentence stimuli involve two transitive events: one with a verb referring to a cruel or criminal act (e.g. "The waitress shoots the cowboy") and one with a verb of witness (e.g. "The secretary sees the waitress"). Our instructions to the subject are to "catch the bad guy" (i.e. to report which of the three characters in a given sentence committed the crime in question). Thus, subjects are tacitly required to interpret the main clause in sentences like "The waitress that the secretary sees shoots the cowboy", and they are tacitly required to interpret the 
relative clause in sentences like "The secretary sees the waitress that shoots the cowboy". For simple sentences, only criminal verbs were used.

The nouns and verbs used in all the studies that follow are listed in Appendix 1 (for English and Italian), and sample sentences for each experiment are listed in Appendix 2 (for English only). For each study, lexical items were randomly assigned to sentence conditions. To ensure that item-specific lexical effects could not influence the results, five different versions were created for each experiment, each with a different random assignment of words to sentence types.

Scoring. Since the notion "number correct" is meaningless in a competition design of this sort, the dependent variable was defined by which noun the subjects chose as the actor. For sentences in which the criminal verb is in the main clause, a score of 1 was given if the subjects chose the first noun in that clause as the actor, and a score of 0 was given if they chose the second noun as the actor. If they failed to give any response at all, or if they chose the third noun (in this case, the internal noun in the relative clause), they were given a score of 0.5 . A score of $100 \%$ would mean that the subject always chose the first noun as actor, a score of $0 \%$ would mean that they always chose the second noun, and a score of $50 \%$ would indicate chance performance. For sentences in which the criminal verb is in the relative clause, a score of 1 was given if the subjects chose the head (external) noun as the actor (e.g. "the waitress" in "the waitress that shoots the cowboy"); a score of 0 was given if they chose the embedded (internal) noun as the actor (e.g. "the cowboy") in "the waitress that shoots the cowboy"). If they failed to give a response on that item, or chose the third noun (in this case, the unmodified noun in the matrix clause), they were given a score of 0.5 . For these analyses, a score of $100 \%$ means that the subjects always chose the head noun as actor, $0 \%$ means that they always chose the embedded noun, and $50 \%$ indicates chance performance.

\section{EXPERIMENT 1: WORD ORDER VARIATIONS}

Subjects. The subjects for this experiment were 25 American college students enrolled in undergraduate courses at the University of California, San Diego, and 25 Italian college students attending the University of Rome "La Sapienza". All participants were native speakers, with minimal bilingual experience (although most have been exposed to a second or third language in a classroom setting).

Materials and Procedure. The 135 sentence stimuli for Experiment 1 were printed in a test booklet, in randomised order. The subjects were 
tested individually in a quiet room. They were told that each sentence contained three characters and a single "bad action", and that their job was to decide which individual committed the crime. They were asked to read each sentence carefully, and to indicate for each sentence "Which character did the bad action" by underlining or circling the relevant noun.

\section{Results and Discussion (see Appendix 3 for statistical details)}

Experiment 1a: Word Order in Simple Sentences. The main aim of this sub-experiment was to determine whether the cross-linguistic differences in interpretation of word order observed in previous studies within the auditory modality are preserved with the visual method adopted here. The 15 simple sentences with no relative clause were analysed in a $2 \times 3$ design, with language (English $v s$ Italian) as a between-subjects variable and word order (NVN, VNN, NNV) as a within-subjects variable. All results were statistically reliable, including main effects of language and word order and a language $\times$ word order interaction (Appendix 3). The interaction is illustrated in Fig. 1, which shows that English subjects have a strong preference for SVO, OSV and VOS interpretations (for NVN, NNV and VNN, respectively), while Italian subjects show a somewhat weaker SVO

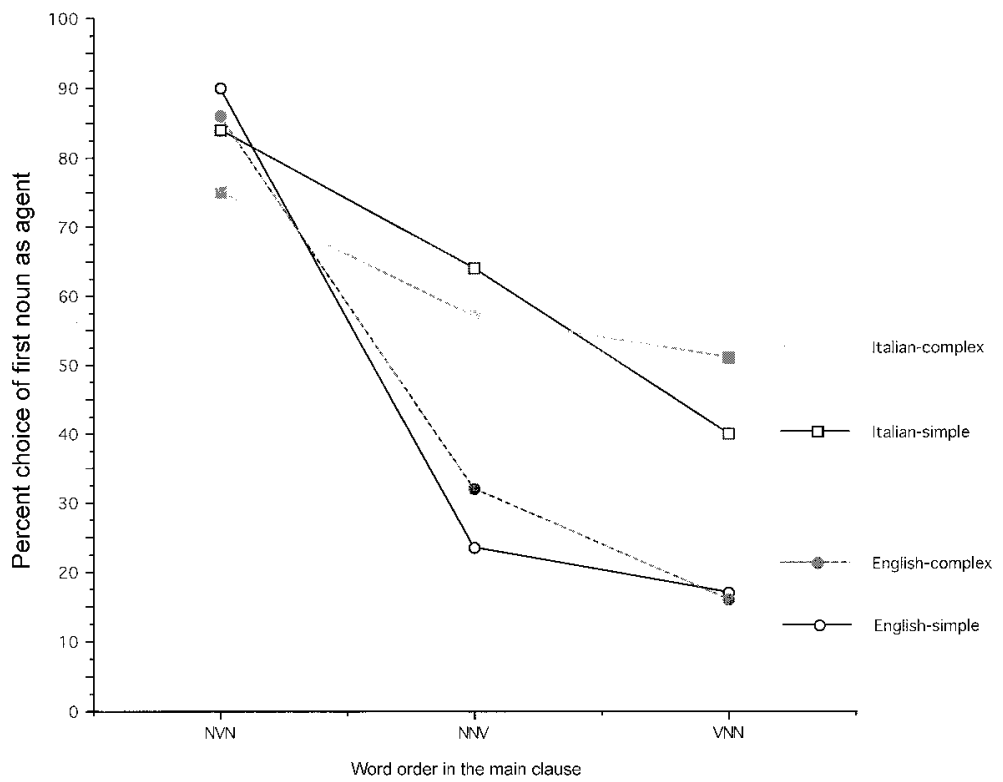

FIG. 1. Language $\times$ word order interaction for agent choice in simple $v s$ complex sentences (Experiments $1 \mathrm{a}$ and $1 \mathrm{~b})$. 
bias, and very small biases towards SOV and VOS. Separate analyses of variance for English and Italian showed that these main effects of word order are also reliable within each language (also in Appendix 3). These findings constitute a visual replication of many previous auditory studies, demonstrating once again that English speakers "trust" word order more than their Italian counterparts.

Experiment 1b: Interpretation of the Main Clause. The main aim of this sub-experiment was to determine whether the cross-linguistic differences in word order use observed in simple sentences are also observed when one of the nouns in the main clause is modified by a relative. This analysis covered the 60 complex sentences in which the criminal verb appears in the main clause, with a verb of witness in the relative clause. The data were subjected to a 2 (English $v s$ Italian $\times 3$ (word order within the main clause) $\times 2$ (position of the relative clause, modifying the first or second noun) $\times 2$ (order within the relative clause) mixed analysis of variance, with language serving as a between-subjects factor and the other variables as withinsubjects factors.

A large number of significant main effects and interactions were found (see Appendix 3). Based on the cue validity principle of the Competition Model, the most important effect in Experiment $1 \mathrm{~b}$ is the language $\times$ word order interaction, which tests the prediction that English and Italian subjects show the same language-specific word order strategies in complex sentences that they show in many studies using simple sentence stimuli. This does indeed appear to be the case. Figure 1 plots the data for simple and complex sentences together (Experiment 1a vs 1b) to facilitate comparison. With added complexity, English subjects continue to pursue a strong SVO strategy for NVN strings (86\% first-noun choice vs $90 \%$ in simple sentences), a strong VOS strategy for VNN strings (16\% first-noun choice vs $17 \%$ in simple sentences), with a somewhat weaker OSV bias on NNV strings (32\% first-noun choice vs $23.5 \%$ on simple sentences), Italian subjects also show a bias towards SVO, although it is slightly flatter in complex sentences (75\% first-noun choice on complex items vs $84 \%$ in simple sentences). They also show a slight flattening of their SOV bias on NNV (58\% first-noun choice on complex items vs $64 \%$ on simple sentences). By contrast, their VOS bias is somewhat stronger on complex VNN strings compared with simpler items (33\% and $42 \%$, respectively).

Overall, these results are in line with our predictions: When sentences are rendered more complex through the addition of a relative clause, English and Italian listeners continue to display the same language-specific word order strategies that we have observed in this and other experiments using simple transitive sentences. The primary effect of complexity lies in a slight flattening of word order strategies for NVN and NNV strings, pushing 
them in the direction of the $50 \%$ chance baseline. The most parsimonious explanation for these small differences is that processing is harder in complex sentence types, adding noise to the data.

On the other hand, the results in Fig. 1 also suggest that some word order types (especially NNV) appear to be more strongly affected by complexity than others. The reason for this became clear when we explored the significant three-way interaction of language, main clause order and position of the relative clause (i.e. modifiying the first $v s$ the second noun). To unpack the three-way effect, separate analyses of variance were conducted for English and Italian. When the Italian data were analysed alone, the only reliable finding was a significant main effect of main clause order (as in Fig. 1). In contrast, the English-only analysis yielded a significant two-way interaction between main clause order and relative clause position, illustrated in Fig. 2. This figure shows that performance on NNV strings is essentially random (i.e. $48 \%$ first-noun choice) when the relative clause modifies the second noun. The reasons for this total parsing failure are clear when we consider a sample item from this set:

11. The waitress the cowboy that the baker hears kills. (NN(NV)V)

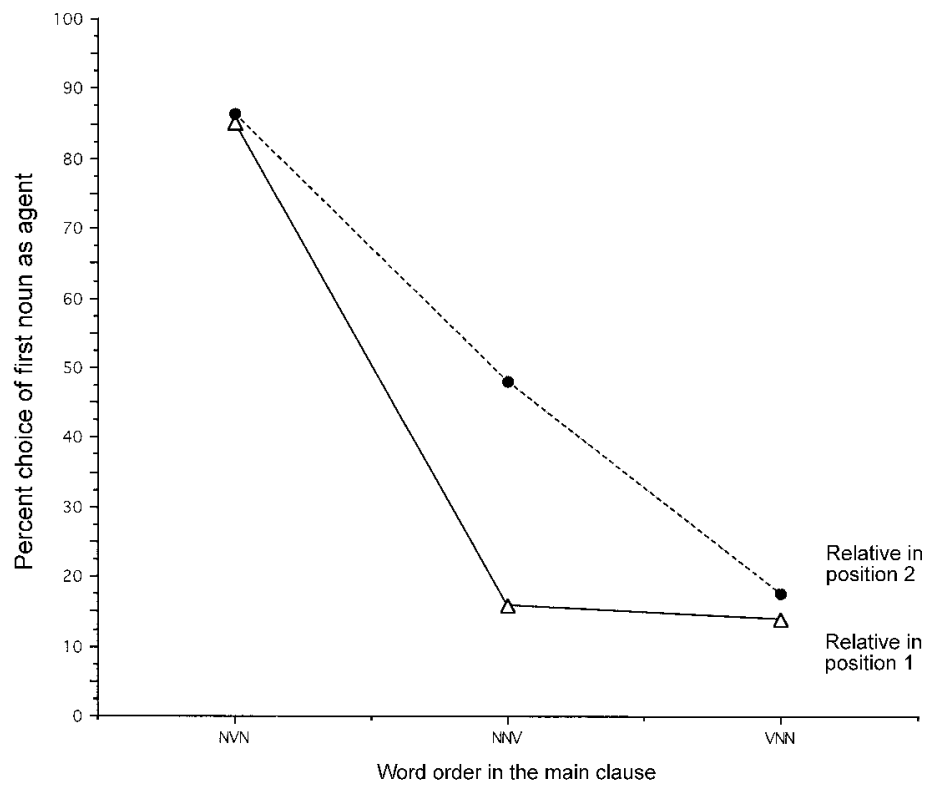

FIG. 2. Effects of main clause order and relative clause position on the interpretation of the main clause, for English only (Experiment 1b). 
Of all the grammatical and ungrammatical stimuli in this complex design, this is by far the most difficult; that is, it is the hardest to parse (three nouns are stacked up before the subject encounters a single verb) and the most deviant (i.e. farthest from any well-informed sentence in the English language). It seems that we have found the outer limits, the point at which our English subjects' ability to assimilate semi-grammatical stimuli to wellformed options in the language finally breaks down.

Experiment 1c: Interpretation of the Relative Clause. The aim of this sub-experiment was to determine whether the cross-linguistic differences that we have observed for both simple and complex main clauses (i.e. English speakers rely more on word order than their Italian counterparts) are also observed within the relative clause itself. This analysis covers the 60 complex sentences in which the criminal verb is located within the embedded clause, with the verb of witness in the matrix clause. The design and the analysis of variance are identical to Experiment 1b. Multiple significant effects were found and are summarised in Appendix 3.

The most important effect from the point of view of the Competition Model is the two-way interaction between language and relative clause order, illustrated in Fig. 3. We pointed out earlier that Italian permits pragmatic word order variation within both the main and the relative clause. Hence relative clause ordering should be a relatively weak cue to agent-object relations for Italians. The results in Fig. 3 show that this prediction is confirmed. Word order biases are in the same direction in both languages; that is, $\mathrm{VN}$ items are interpreted as subject-relatives (e.g. "The waitress that shoots the cowboy") and NV items are interpreted as object-relatives (e.g. "The waitress that the cowboy shoots"). However, this effect is stronger in English. On VN items, English subjects choose the head noun as agent $85 \%$ of the time, compared with $73 \%$ in Italian. On NV items, English subjects choose the head noun only $15 \%$ of the time (i.e. $85 \%$ object-relative interpretations), compared with $35.5 \%$ for Italian (i.e. $64.5 \%$ object-relative interpretations). Hence, even in the absence of conflicting morphological or semantic information, Italian subjects rely less on word order to understand a relative clause.

The most complex effect in Experiment 1c was a three-way interaction of language, main clause order and relative clause order. To explore this interaction further, we conducted separate analyses for English and Italian. These analyses showed that word order is the only factor influencing relative clause interpretation in English (i.e. relative clause order was the only significant effect, in the predicted direction). In contrast, the Italianonly analysis yielded main effects of word order at both levels of the sentence (main clause and relative clause), together with a significant twoway interaction. Examination of cell means yielded a straightforward 


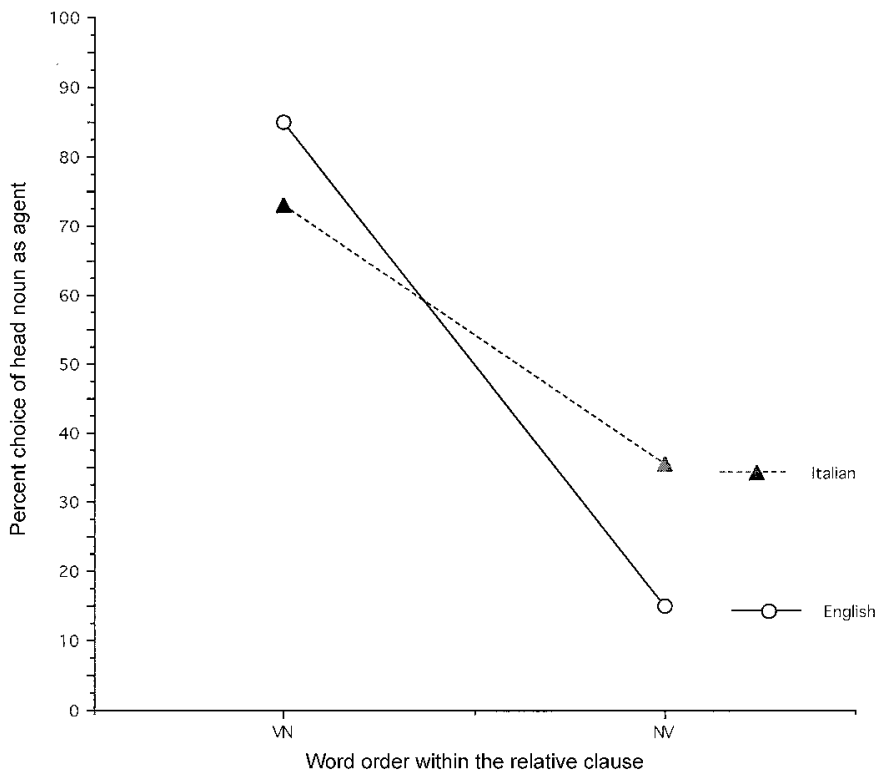

FIG. 3. Effect of relative clause order on the interpretation of the relative in English and Italian (Experiment 1c).

interpretation of these effects: A canonical interpretation of the relative clause is less likely in Italian when a highly marked and difficult word order type is used in the main clause. On VN items, Italians choose the preferred subject-relative (VO) interpretation $77 \%$ of the time if the matrix clause is a canonical NVN, compared with $71 \%$ for $\mathrm{VNN}$ and $72 \%$ for NNV. On $\mathrm{NV}$ items, Italians choose the preferred object-relative (SV) interpretation of $\mathrm{NV}$ clauses $71.5 \%$ of the time when the matrix clause is a canonical NVN, $70 \%$ when the matrix clause is VNN, versus a near-random $53 \%$ on NNV. These subtle but reliable effects testify further to the fragile and pragmatically conditioned nature of word order strategies in Italian, compared with the robust, context-independent word order effects that are observed in English.

\section{Summary of Experiment 1}

We have shown that language-specific word order strategies are observed not only in simple transitive sentences, but also in complex sentences in which one of those nouns is modified by a relative clause. English subjects show robust and consistent word order profiles in the main clause, for all three word order configurations: NVN is interpreted as SVO, NNV is interpreted as OSV and VNN is interpreted as VOS. They also display 
strong word order biases within the relative clause itself, interpreting VN orders as VO (subject relatives, where the agent role is assigned to the head noun) and NV orders as SV (object relatives, where the agent role is assigned to the embedded noun). Italians display their own word order preferences within the main clause (NVN as SVO; NNV as SOV; VNN as VOS), with or without a relative, and they display reliable effects of word order within the relative clause, similar in direction to those observed in English. However, the use of word order is invariably weaker and less consistent in Italian than it is in English, at both levels of the sentence, in line with the cue validity principle of the Competition Model. When simple and complex sentences are compared, the effects of complexity are rather small, restricted primarily to a slight "flattening" of effects in the direction of the $50 \%$ random baseline. This is particularly true for English items in the order NNV, where a pile-up of nouns prior to the main verb seems to neutralise the OSV strategy that is usually employed for these sentence types.

\section{EXPERIMENT 2: SUBJECT-VERB AGREEMENT VARIATIONS}

In all of our previous experiments, Italian subjects made extensive use of subject-verb agreement to assign sentence roles, far more than their English counterparts. When sentences contain a competition between agreement and word order, agreement information "wins" in Italian and word order "wins" in English. Once again, however, we did not know if these cross-linguistic differences would hold up for complex sentence types. This was the main aim of Experiment 2. As described in the General Methods, the stimuli for Experiment 2 were designed to examine competing and converging effects of word order and agreement, within simple sentences (restricted to NVN order only), within the main clause in complex sentences (also restricted to NVN order only) and within the relative clause itself (both $\mathrm{VN}$ and $\mathrm{NV}$ ).

Subjects. The subjects for this experiment were the same 25 American and 25 Italian college students who participated in Experiment 1 . The order of presentation of the experiments was randomised, with approximately half of the subjects participating first in Experiment 1 and half participating first in Experiment 2.

Procedure. The 375 sentence stimuli for Experiment 2 were printed in a separate test booklet, in randomised order. The instructions and test procedures were identical to those used in Experiment 1. 


\section{Results and Discussion (see Appendix 3 for statistical details)}

Experiment 2a: Agreement in Simple Sentences. The main aim of this sub-experiment was to provide a visual replication of the cross-linguistic differences in reliance on subject-verb agreement that we have observed in auditory studies. This part of the experiment contains 15 sentences, 5 in each of three cells (ambiguous agreement; agreement in number with the first noun; agreement in number with the second noun), analysed within a mixed 2 (language) $\times 3$ (agreement conditions) analysis of variance. All three effects were reliable (language, agreement and the language $x$ agreement interaction). The interaction is illustrated in Fig. 4, which shows that subject-verb agreement is a much stronger cue in Italian than it is in English. Recall that all the stimuli in Experiment 2 have the order NVN within the main clause. English subjects are overwhelmingly more likely to choose the first noun as agent on such stimuli: $100 \%$ on sentences with no morphological contrast, $100 \%$ on sentences in which SVO and agreement converge, and $92 \%$ on items in which SVO and agreement are in competition. A separate one-way analysis of variance for English subjects alone showed that the effect of agreement does not even reach significance

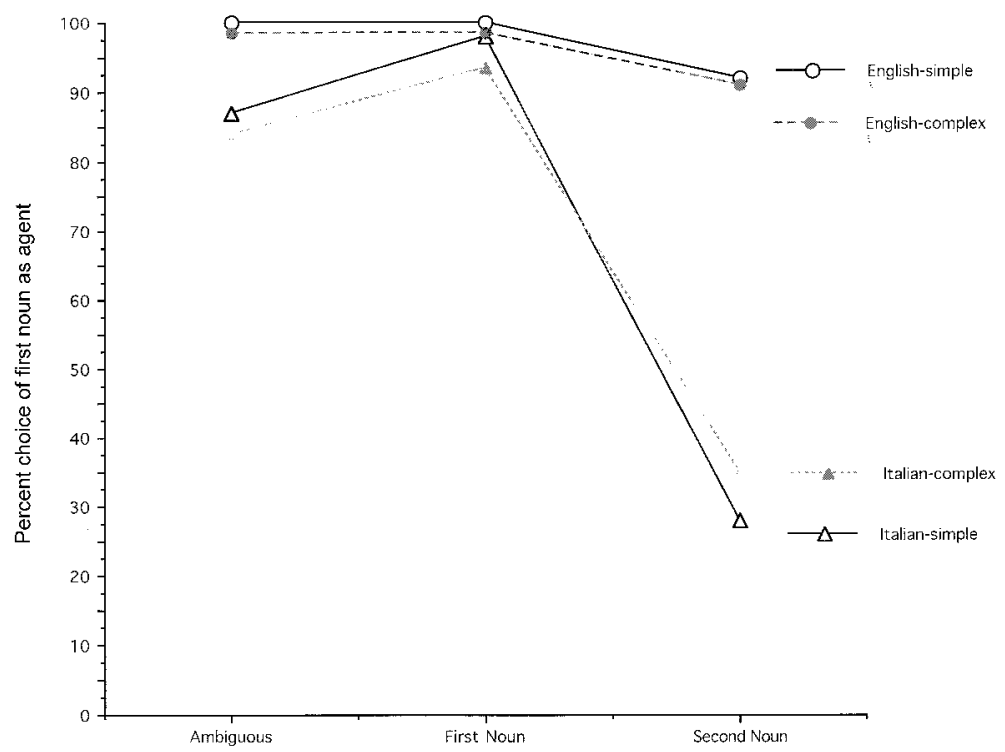

Agreement conditions in the main clause

FG. 4. Effects of language and main clause agreement on the interpretation of the main clause in simple $v s$ complex sentences (Experiments 2a and 2b). 
in this language. By comparison, Italians choose the first noun only $87 \%$ of the time on morphologically ambiguous sentences, compared with $98 \%$ on items in which SVO and agreement converge, and $28 \%$ on items in which SVO and agreement point in other directions (i.e. agreement wins the competition). A separate one-way analysis of variance for Italian alone yielded a robust main effect of agreement. In short, this experiment in the visual modality replicates our previous findings for English versus Italian using auditory stimuli: (1) canonical word order "wins" in English, while subject-verb agreement "wins" in Italian; and (2) canonical word order is weaker in Italian even when there is no competition from other sources.

Experiment 2b: Interpretation of the Main Clause. The main aim of this sub-experiment was to determine whether the cross-linguistic differences in agreement that we have observed in simple sentences are also seen in the main clause of complex sentences. The design involved a total of 180 sentences, analysed within a 2 (language) $\times 3$ (levels of agreement in the main clause) $\times 3$ (levels of agreement in the relative clause) $\times 2$ (order within the relative clause) $\times 2$ (placement of the relative after the first or the second noun) design, with language serving as a between-subjects factor and all other variables as within-subjects factors. A large number of significant main effects and interactions were found (see Appendix 3), including a four-way interaction of language, main clause agreement, relative clause agreement and order in the relative clause.

The largest effect and the most important for our purposes here is the interaction between language and subject-verb agreement in the main clause, illustrated in Fig. 4 (where it is plotted against the analogous effect for simple sentences from Experiment $2 \mathrm{a}$ in order to facilitate comparison). As Fig. 4 shows, our predictions were confirmed: The same crosslinguistic differences are observed in simple and complex sentence types; that is, SVO word order "wins" in English and subject-verb agreement "wins" in Italian. The only difference between Experiment $2 \mathrm{a}$ and Experiment $2 \mathrm{~b}$ appears to be a slight flattening of results on complex items. In other words, complexity does exact a small toll, but the overall pattern is preserved. This is the most important effect in Experiment 2b, but the minor effects deserve exploration. To simplify the task of interpreting a four-way interaction, we again conducted separate analyses of variance for English and Italian.

In the English analysis, two effects reached significance: a main effect of order within the relative clause, and an interaction between relative clause order and position of the relative within the main clause. Cell means for this interaction break down as follows. When the relative clause modifies the first noun, English subjects choose that noun as the actor in the main clause $93 \%$ of the time with a VN relative versus $97.5 \%$ with a NV relative. 
When the relative clause modifies the second noun, that noun is chosen as the object of action $98 \%$ of the time with a $\mathrm{VN}$ relative versus $97 \%$ with a NV relative. The outliers here (at 93\%) are sentences of the form $\mathrm{S}(\mathrm{VO}) \mathrm{VO}$. To be sure, this is a very small effect, but it runs directly counter to predictions based on the Parallel Function Hypothesis (Sheldon, 1974), according to which the "subjecthood" of the first noun in a NVN sentence should be enhanced if that noun also plays the subject role within the relative clause. Why should this be? We suspect that our English subjects are occasionally seduced into a parsing error on sentences of this type. Consider the following item:

(12a.) The ballerina that sees the policeman shoots the cook. $(\mathrm{N}(\mathrm{VN}) \mathrm{VN})$

This item may be accidentally parsed as (12b) or (12c):

(12b.) The policeman shoots the cook. (NVN)

(12c.) The ballerina sees the policeman that shoots the cook. $(\mathrm{NVN}(\mathrm{VN}))$

Whether or not this is the correct explanation, we should bear in mind that the difference is relatively small (i.e. 93 vs 98\% first-noun choice), a minor perturbation of an overwhelming tendency for English subjects to apply SVO interpretations within the main clause.

In the separate analysis of variance for Italian, two effects reached significance: a large effect of main clause agreement (see Fig. 4) and a small three-way interaction of main clause agreement, relative clause agreement and relative clause order. Examination of the cell means for this three-way interaction suggests that it is entirely due to sentences that are morphologically ambiguous in the main clause, where Italians do not have their favourite cue available (see Table 1). In the absence of their favourite cue, they are forced to rely primarily on SVO word order. However, in contrast to their English counterparts, they do not "trust" SVO very much, and can be thrown off by other combinations of information. In fact, the smallest effect of SVO (i.e. $73.5 \%$ choice of the first noun) occurs in morphologically ambiguous main clauses that contain a competition within the relative clause: The relative is in the non-canonical order NV (favouring an object-relative interpretation), but the head noun agrees with the embedded verb (favouring a subject-relative interpretation). Bearing in mind that subjects are supposed to interpret the main clause in this part of the experiment, in principle it should be possible to ignore the relative clause altogether. Indeed, the corresponding sentences do not bother English subjects at all, but they do bother Italians. This may occur 
TABLE 1

Effects of Main Clause Agreement, Relative Clause Agreement and Relative Clause Order on Interpretation of the Main Clause, for Italians Only (Experiment 2b)

Main Clause

Relative Clause Agreement (\%)

Agreement

Ambiguous

Head Noun

Embedded Noun

Ambiguous

$\mathrm{VN}$

88.0

88.0

82.0

NV

80.0

73.5

92.5

First noun

agrees

$\mathrm{VN}$

97.0

95.5

91.0

NV

93.0

92.5

92.0

\section{Second noun}

agrees

VN

33.0

36.0

38.5

NV

37.0

35.0

34.5

for two reasons (which are not mutually exclusive), either because processing load has become so heavy that response moves towards the random baseline (i.e. a noise overload), or because the highly marked nature of the relative clause persuades Italians to be suspicious of canonical interpretations at every level. Evidence in favour of the latter interpretation comes from our previous studies of simple sentences in Italian, which showed that Italians are likely to reject an SVO interpretation in favour of OVS when contrastive stress is used on either noun (MacWhinney et al., 1984), or when the sentence contains a morphologically ambiguous clitic pronoun (Devescovi, 1992). The story is complex, but the basic intuition is a simple one: Italians do not trust canonical SVO word order, and they are willing to suspend default SVO interpretations under heavily marked or unusual morphological, semantic, pragmatic and/or prosodic conditions.

Experiment 2c: Interpretation of the Relative Clause. The aim of this sub-experiment was to determine whether the cross-linguistic differences in agreement that we have observed in main clauses (simple or complex) are also observed when participants have to interpret the relative clause. Hence the criminal verb is located in the relative clause, and the verb of witness in the main clause. Otherwise, the design is identical to that of Experiment $2 \mathrm{~b}$, involving a total of 180 sentences, analysed within a 2 (language) $\times 3$ (levels of agreement in the main clause) $\times 3$ (levels of agreement in the relative clause) $\times 2$ (order within the relative clause) $\times 2$ 
(placement of the relative after the first or the second noun) design, with language serving as a between-subjects factor and all other variables as within-subjects factors. The analysis of variance yielded a large number of significant effects and these are summarised in Appendix 3.

The most important effect for our purposes here is the three-way interaction of language, relative clause agreement (which should be strong in Italian and weak in English) and relative clause order (which should be strong in English and weak in Italian). This interaction is illustrated in Fig. 5, which shows that all of our predictions are roundly confirmed. In interpreting the relative clause, English speakers rely overwhelmingly on word order: items in the VN order are interpreted as subject-relatives, and items in the NV order are interpreted as object-relatives. Competing information from agreement within the clause has virtually no effect in English (see below). In contrast, Italians rely overwhelmingly on agreement information: If the head noun agrees with the embedded verb, a subject-relative interpretation is assigned; if the embedded noun agrees with the embedded verb, an object interpretation is far more likely. Italians do have the same word order biases as their English counterparts (VN as subject-relative; NV as object-relative), but they are relatively weak, showing up primarily on morphologically ambiguous items. To

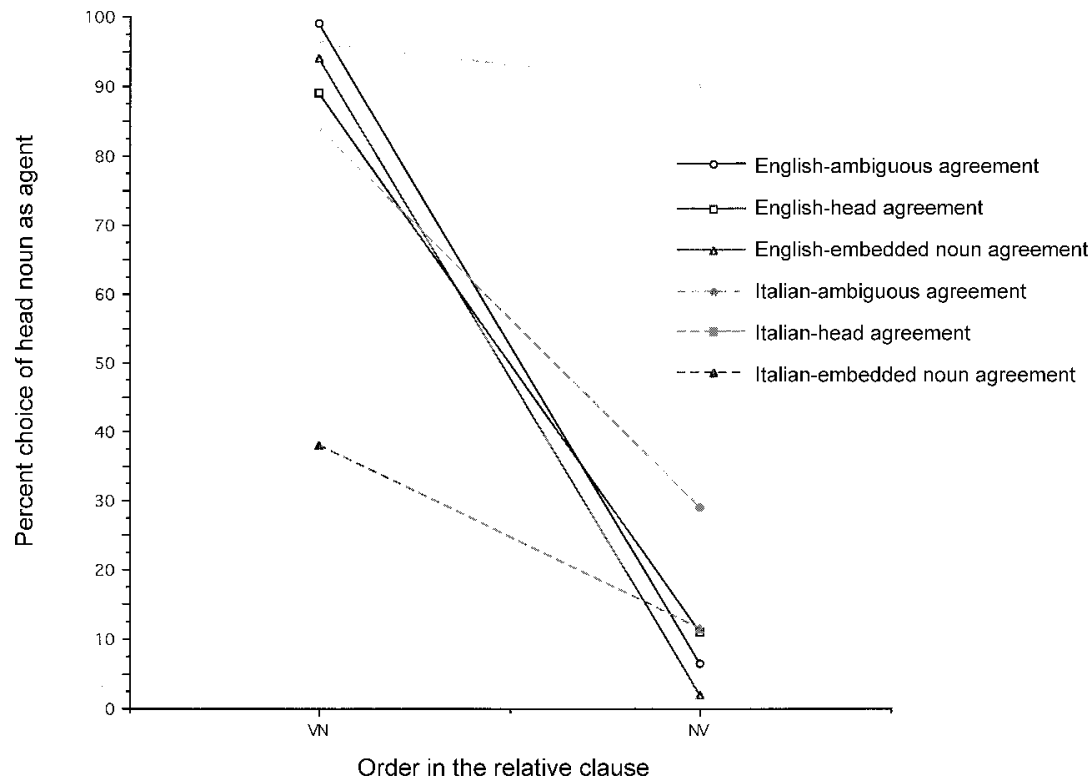

FIG. 5. Effects of relative clause order and relative clause agreement on the interpretation of the relative in English vs Italian (Experiment 2c). 
explore these effects and the other complex interactions in this data set in more detail, separate analysis of variance were again conducted for English and Italian (Appendix 3).

The results for the English analysis are crystal-clear: The only effect to reach significance at the $P<0.01$ level was the robust main effect of order within the relative clause. Nothing else even approached significance. This means, of course, that all of the complex interactions listed in Appendix 3 are coming from Italian.

Turning to the Italian effects, the largest and most imortant of the twoway interactions in Italian involves the relationship between order and agreement within the relative clause, illustrated in Fig. 5. This interaction shows that agreement wins out over default word order across the board in Italian, but competition between factors does exact a small toll. On VN items, Italians choose the head noun as subject $84 \%$ of the time if there is no competition from morphology (the default subject-relative interpretation), $96 \%$ when morphology and word order lead to the same interpretation (a convergence between agreement and the default interpretation), but only $38 \%$ of the time when morphology and word order are in competition (corresponding to $62 \%$ object-relatives, the opposite of English interpretations on the corresponding items). On NV items, Italians choose the head noun as subject $29 \%$ of the time on morphologically ambiguous items (corresponding to $71 \%$ default object-relative interpretations), 11\% when morphology and word order lead to the same answer (89\% object-relatives, reflecting the convergence of agreement and default order), and $90 \%$ when agreement and word order are in competition (overwhelming preference for a subject-relative assignment, the exact opposite of performance by English subjects on analogous items).

The two remaining interactions can be summarised as follows. Regardless of agreement conditions within the matrix clause, the huge effect of relative clause agreement in Italian always runs in the same direction. However, this effect is slightly flatter on non-canonical items in which the second noun in the main clause agrees with its verb (i.e. items that are likely to receive an OVS interpretation). This may be one more example of when markedness (in the main clause) adds to overall complexity, pushing performance (in the relative clause) slightly closer to the chance baseline. The effect of relative clause agreement is also slightly smaller (by a few percentage points) when the relative clause is in the second position. The reason for this latter finding is not at all obvious. However, a look through all the cells in this complex interaction revealed an interesting oddity: the flattest agreement effect was observed on items like the following (from Appendix 2):

(13.) The secretary see the cooks that shoot the doctors. 
These are items in which the verb of witness in the main clause agrees with the second noun (which should force an OVS interpretation), and where the relative clause modifies the second noun, in the $\mathrm{VN}$ order, with agreement on the embedded noun (which should force a VS interpretation). In addition to the fact that these items involve a high degree of competition and non-canonical form, they have another peculiar characteristic: If Italians use morphology at all levels to make their assignments (which is usually the case), they arrive at an interpretation in which the crime victim is busy watching somebody else while he himself is getting murdered! By reinterpreting these sentences, Italians can restore a more pragmatically felicitous situation in which it is the criminal who is watching out for other individuals who might be on the scene. Note, however, that such pragmatic biases are small, and play their greatest role in highly marked sentences that are particularly difficult to interpret (even though they are grammatically correct in the Italian language).

\section{Summary of Experiment 2}

The largest effects by far in this experiment are the ones predicted by the Competition Model: English listeners rely exclusively on word order to interpret the relative clause, whereas Italians rely overwhelmingly on agreement information, a bias that only breaks down when processing is maximally overloaded. These results complement our findings in Experiment 1, where English word order biases only break down under the worst possible processing conditions. We did find some minor effects in both experiments that are not predicted by the model, which we attribute to a breakdown or "softening" of sentence processing due to combinations of complexity, markedness and pragmatic felicity. These effects are interesting, and may be worthy of further investigation, but they are very small compared with the large cross-linguistic findings predicted by the model.

In view of previous complaints about the use of ungrammatical sentences in previous studies testing the Competition Model, we want to remind readers that all of the sentence types in Experiments 1 and 2 are grammatical in Italian, although some items are so pragmatically marked that they stretch the definition of grammaticality. Many of the sentence types in Experiments 1 and 2 are frankly ungrammatical in English, but it is clear that English subjects know exactly what to do with them in all but a few cases. Despite the difficult and often very odd nature of these materials, English and Italian subjects respond with consistent and language-specific interpretations that are predicted by cue validity in their respective languages.

These results suggest to us that the strategies used by English and Italian subjects in our experiments bear a consistent relationship to the strategies 
used in everyday conversation. However, this conclusion would be strengthened if we could show that the same cross-linguistic effects hold up in an "on-line" (timed) paradigm. First, if similar profiles of agent assignment are obtained when subjects are tested under time pressure, with relatively fast reaction times, then we may conclude with greater confidence that our findings are related to sentence interpreation strategies that listeners use in everyday life. Second, we should find cross-linguistic differences in reaction time profiles, reflecting convergence and/or competition between cues that differ in strength in English and Italian. We would, for example, expect word order to create larger effects in English; conversely, we would expect to find more effects of agreement in Italian. This brings us to Experiments 3 and 4, on-line versions of the two complex experiments that we have just described. In addition to providing a further test of the Competition Model, these on-line studies may yield new insights into the processing demands associated with complex sentences, illuminating the interplay between universal and languagespecific factors in sentence processing.

\section{EXPERIMENT 3: WORD ORDER VARIATIONS ON-LINE}

Subjects. The subjects for this experiment were 25 American college students enrolled in undergraduate courses at the University of California, San Diego, and 25 Italian college students attending the University of Rome "La Sapienza". All participants were native speakers, with minimal bilingual experience (although most have been exposed to a second or third language in a classroom setting). None had participated in Experiments 1 and 2.

Materials and Procedure. In this on-line version, the same 135 sentence stimuli used in Experiment 1 were presented one at a time on a computer screen, at a MacIntosh SI workstation controlled by the Carnegie Mellon Experimental Control Shell (ECS), a predecessor of the PsyScope System (Cohen, MacWhinney, Flatt, \& Provost, 1993). (For eight subjects in this experiment and six in Experiment 4, administration was switched from ECS to the updated PsyScope system. Preliminary analyses indicated that the two systems did not yield significant differences in performance; data are pooled across ECS and PsyScope in all subsequent analyses.) Subjects were tested individually in a quiet room. The instructions were identical to Experiments 1 and 2, except that subjects were asked to press a button on the Carnegie Mellon button box as soon as they knew which actor had carried out the "bad action". After each button press, they were asked to say the name of the chosen agent aloud; this response was recorded 
manually by the experimenter. If subjects failed to respond within a 5-sec time window, the test sentence disappeared from the screen and the next trial began.

Scoring. Scoring of the manually recorded agent assignments (i.e. "who did it?") was identical to the scoring used for the test booklets in Experiments 1 and 2, with one exception: Trials in which the subject failed to respond within the 5-sec time window were eliminated prior to analysis of either the decision or the reaction time data, and scores for that cell were averaged to reflect performance on the remaining items. Such nonresponses comprised $1.37 \%$ of all responses for English subjects and 1.30\% of all responses for Italian subjects in Experiment 3.

\section{Results and Discussion (see Appendices 4 and 5 for statistical details)}

Before exploring the reaction time results obtained in this experiment, we began by examining results for agent choice, to determine whether the results obtained off-line in Experiment 1 replicate when subjects are placed under time pressure. All of these analyses described for Experiment 1 were repeated using experiment ( 1 vs 3 ) as a between-subjects factor. Appendix 4 reports only those main effects and interactions that involved the factor "experiment". Despite the complexity of these analyses, the results were strikingly similar in the off-line and on-line versions. There were a few small but significant effects involving experiment as a factor. In general, these discrepancies involved a sharpening of word order effects in the on-line version, a tendency that was most evident in English. However, all of these between-experiment findings were relatively small, and none of them reflected a change in the direction of results compared with Experiment 1. Therefore, in the interests of parsimony, we will restrict our discussion to reaction time findings.

Experiment 3a: Word Order Variations in Simple Sentences. The aim of this sub-experiment was to determine whether cross-linguistic differences in reliance on word order are reflected in reaction time. A 2 (English vs Italian) $\times 3$ (word order in the main clause) analysis of variance yielded a significant main effect of word order and a significant interaction between language and word order (see Appendix 5 for statistical details). The main effect of language was not reliable, indicating that English and Italian subjects take approximately the same amount of time to read these sentences (i.e. a mean of $2439 \mathrm{msec}$, less then $2.5 \mathrm{sec}$ from stimulus onset). These relatively fast reaction times (less then $600 \mathrm{msec}$ per word) suggest to us that subjects are applying familiar strategies borrowed from those 
that are used in everyday life. The interaction between language and word order is illustrated in Fig. 6, which shows that English subjects responded faster than Italians on NVN (1895 vs $2092 \mathrm{msec})$ and VNN ((2310 vs $2661 \mathrm{msec}$ ), and slower on NNV (3024 vs $2664 \mathrm{msec}$ ). Hence we may conclude that word order has a larger effect on the processing of simple sentences in English than Italian, an effect that is compatible with crosslinguistic differences in agent choice.

Experiment 3b: Interpretation of the Main Clause. The main aim of this sub-experiment was to determine whether cross-linguistic differences in reliance on word order are reflected in reaction times, for complex as well as simple sentences. In addition, we hoped that this analysis would yield new information about the specific processing costs associated with sentence embedding, in canonical versus non-canonical word order types. The materials and design were identical to those of Experiment $1 \mathrm{~b}$. Significant findings (listed in Appendix 5) included main effects of all variables, a three-way interaction of language, main clause and relative clause order, and a three-way interaction of language, main clause order and relative clause position. Although this is an intricate nest of findings,

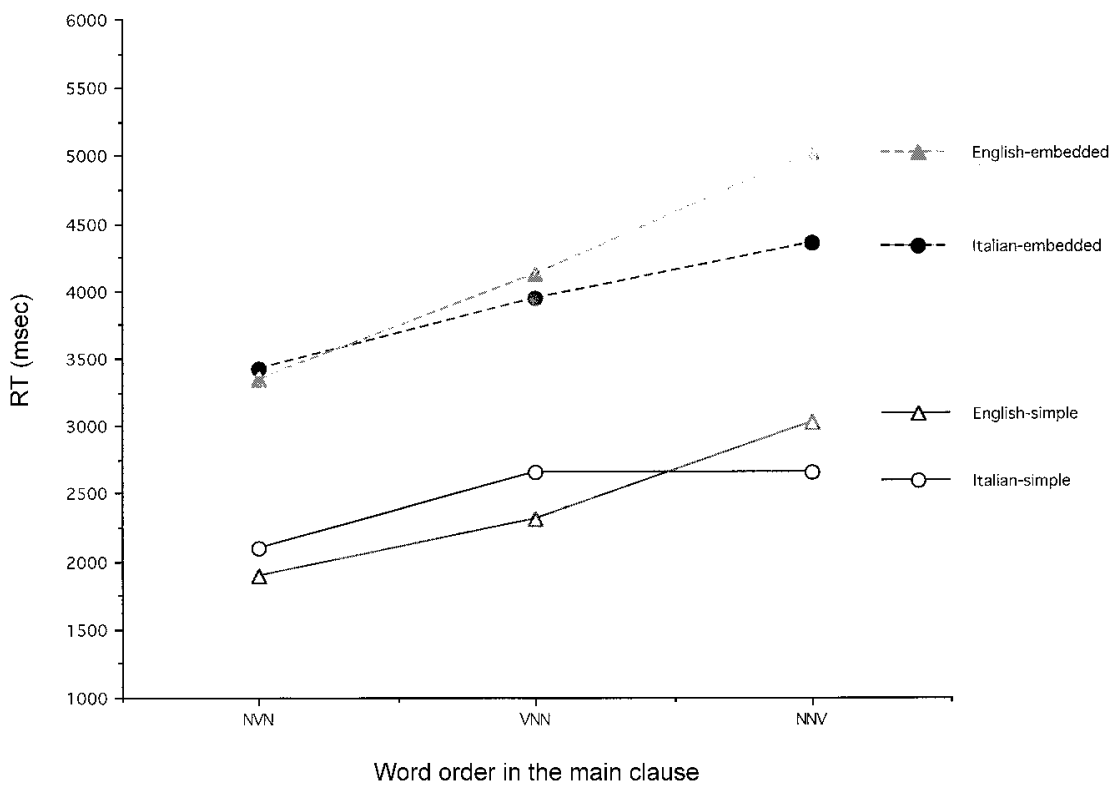

FG. 6. Reaction times for the interpretation of the main clause in English and Italian, in simple $v s$ embedded sentences (Experiments $3 \mathrm{a}$ and $3 \mathrm{~b}$ ). 
all of them are quite sensible, reflecting variations in processing load that follow from the strategies used in each language.

First, the main effect of order and its intereaction with language are similar to the results that we have already encountered for simple sentences: Canonical NVN is the fastest order in both languages (averaging $3341 \mathrm{msec}$ in English and $3423 \mathrm{msec}$ in Italian), followed by VNN (4172 msec in English and $3950 \mathrm{msec}$ in Italian), with the slowest RTs observed on NNV items (5018 msec in English and $4358 \mathrm{msec}$ in Italian). Of course, these reaction times are considerably slower than the averages obtained with simple sentences, reflecting the additional time required to read and interpret sentences with an embedded clause. The very sharp increase in RTs for NNV reflects the fact that these items suffer the most from centre embedding (i.e. N(rel)NV and NN(rel)V are both centre-embedded items). This situation weights most heavily on English subjects, who are struggling to apply their non-canonical OSV strategy to the main clause in these difficult embedded structures. It has less of an effect on Italian subjects, who have very weak biases on both VNN and NNV, and treat the two indifferently with or without an embedded clause. The language $\times$ main clause order interaction for Experiment $3 \mathrm{~b}$ is also presented in Fig. 6, to facilitate comparison of performance in simple versus complex sentences.

Second, the effect of relative clause order on interpretation of main clauses reflects the additional processing load that arises with the presence of a non-canonical relative (even though subjects do not have to interpret the relative in this section of the experiment). Collapsed over language and other sentence effects, reaction times to interpret the main clause averaged $3898 \mathrm{msec}$ when the relative clause was a canonical VN, compared with $4190 \mathrm{msec}$ when the relative as a non-canonical NV. The interaction between language and relative clause order shows us that this effect of canonicity is much worse for English subjects. In fact, separate analyses of variance within each language showed that the clause order effect was highly reliable for English, but not for Italian. The three-way interaction of language, main clause order and relative clause order is illustrated in Fig. 7, which shows that English subjects find it especially difficult to interpret items in which the main clause is in the order NNV and the embedded clause in the order NV, a situation of maximal embedding with noncanonical word order at both levels of the sentence (e.g. "The secretary the cowboy that the policeman shoots sees"). These conditions are apparently far less taxing for Italians, who come to the task with less pronounced word order biases at either level.

Finally, the position effects also reflect the problem posed by centre embedding (i.e. interruption of the main clause). This problem is particularly serious for English subjects, who are trying hard to use their 


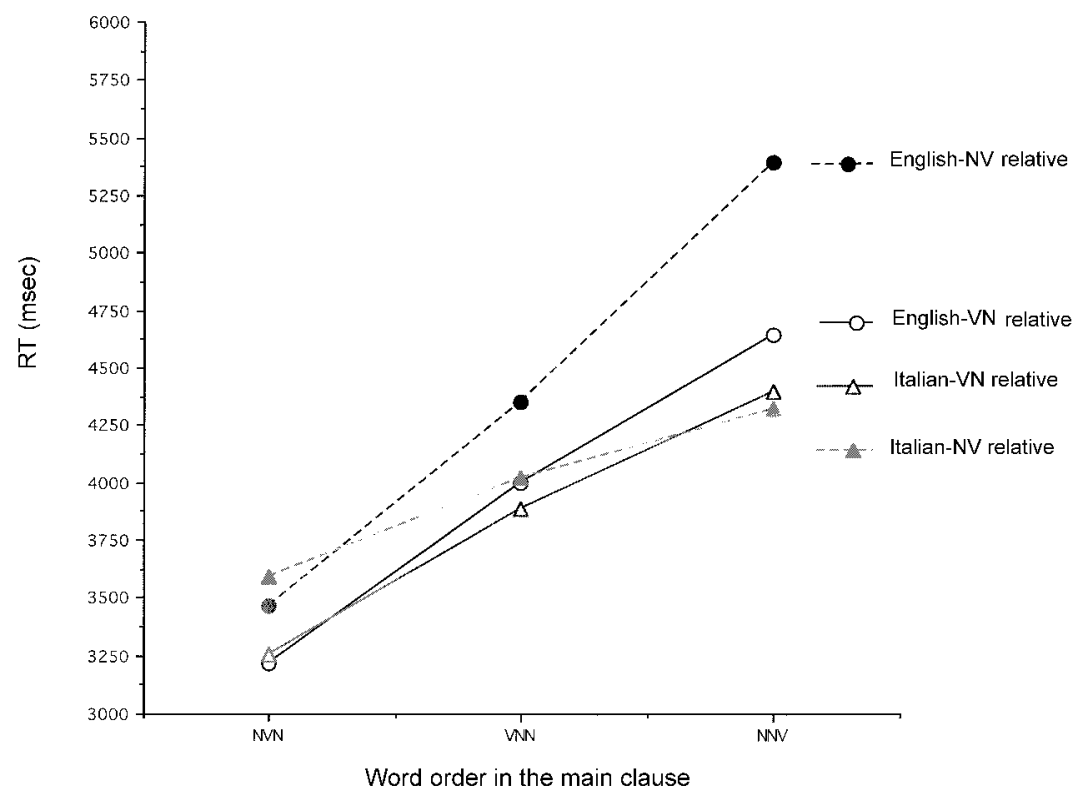

FIG. 7. Reaction times for the interpretation of the main clause as a function of language, order in the main clause and order in the relative (Experiment $3 b$ ).

word order strategies in every case. Overall, the main effect of relative clause position reflects slower RTs when the relative modifies the first noun in the main clause (mean $=4140 \mathrm{msec}$ ) and faster RTs when the main clause modifies the second noun (mean $=3946 \mathrm{msec})$. However, this position effect is accounted for entirely by VNN and NVN strings, where early placement of the clause results in a centre embedding, whereas late placement does not. On NNV strings where centre embedding occurs regardless of relative noun position, faster results are obtained with early placement. In fact, NNV items present the most severe problems of centre embedding overall, a situation that is apparently exacerbated when the relative modifies the second noun (giving sentences of the form $\mathrm{NN}(\mathrm{rel}) \mathrm{V}$ ). This is true for both languages, but it is especially true for English, as we can see from the three-way interaction of language, main clause order and relative clause position illustrated in Fig. 8.

To summarise the findings for this section, we again find significant cross-linguistic differences in the direction and magnitude of word order effects in the main clause, similar to the effects we have observed in many studies using simple transitive sentences with no embedding. Reaction times reflect larger effects of word order for native speakers of English, 


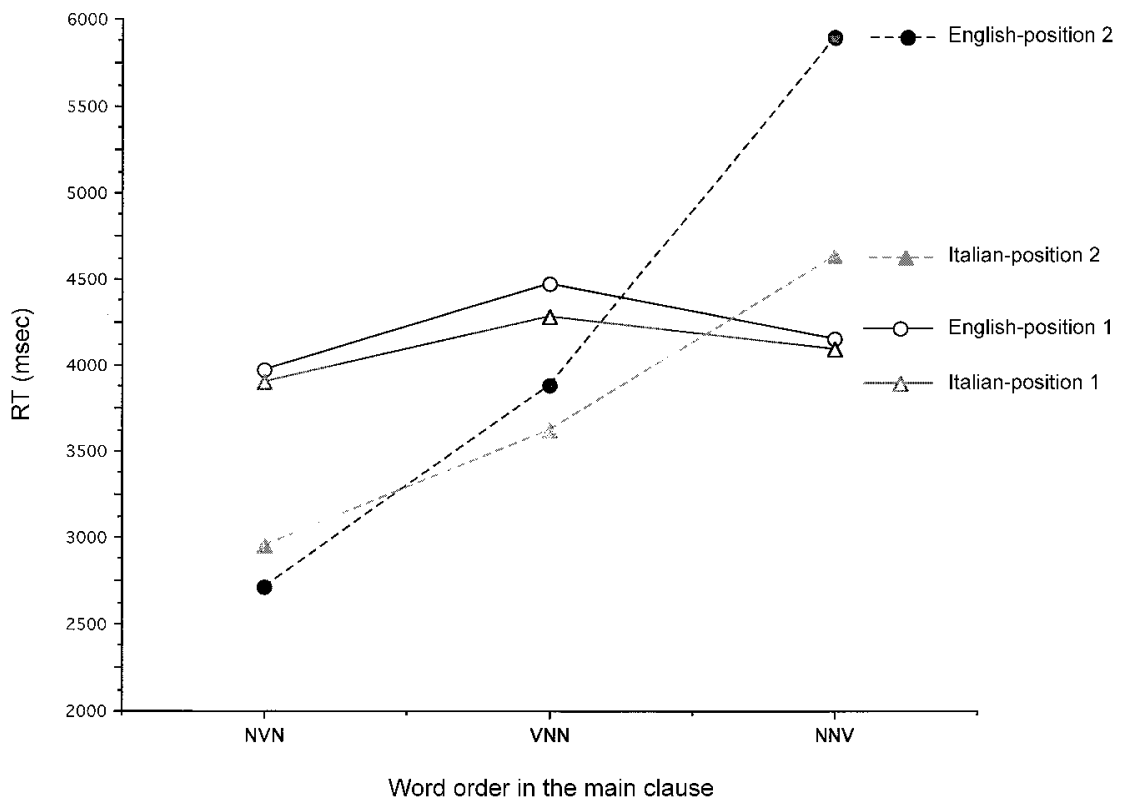

FIG. 8. Reaction times for the interpretation of the main clause as a function of main clause order and relative clause position in English $v s$ Italian (Experiment 3b).

who also pay a greater price than Italians do for centre embedding and non-canonical order.

Experiment 3c: Interpretation of the Relative Clause. The main aim of this sub-experiment was to determine whether the cross-linguistic differences in RT to word order variations reported for simple and complex sentences are also observed within the relative clause itself. The materials and design are identical to those of Experiment 1c, covering the 60 complex sentences in which the criminal verb is located within the embedded clause, with the verb of witness in the matrix clause. The analysis of variance yielded a large number of significant effects, which are summarised in Appendix 5.

Again, although this is an intricate set of statistical findings, their interpretation is relatively straightforward. Most of the effects in this analysis are in the same directions for English and Italian, and most of them reflect three general factors: processing is slower in the presence of non-canonical word orders at either level (relative or main clause), processing is slower with heavily embedded items, and interpretations of the relative clause tend to be faster when that clause occurs early in the sentence (modifying the first noun). As we shall see, the second factor (a 
disadvantage for centre embedding) and the third factor (an advantage of early placement of the relative clause within the sentence; i.e. an "early bird" effect) work against each other in some sentence types.

First, the effect of main clause order (significant in both languages) means that subjects find it easier to interpret the relative clause when the matrix clause is a canonical NVN (mean RT $=3516$ msec for NVN, $4123 \mathrm{msec}$ for VNN and $4134 \mathrm{msec}$ for NNV). This is a straightforward effect of processing load. Similarly, the effect of relative clause order (also significant in both languages) means that interpretation of the relative clause is faster when that clause is a canonical VN $($ mean $=3742 \mathrm{msec})$ and slower when it is a non-canonical NV (mean $=4107 \mathrm{msec})$. This can also be interpreted as an effect of processing load and/or an effect of frequency of clause types ( $\mathrm{VN}$ is more frequent than $\mathrm{NV}$ in both languages). The interaction between main clause and relative clause order is illustrated in Fig. 9, which shows that the fastest reaction times are observed when both levels of the sentence are canonical (NVN sentences with VN relatives). In separate analyses, this interaction only reached significance in English (Appendix 5).

The effects involving relative clause position are a bit more subtle, but they derive primarily from the conflict between availability (an advantage

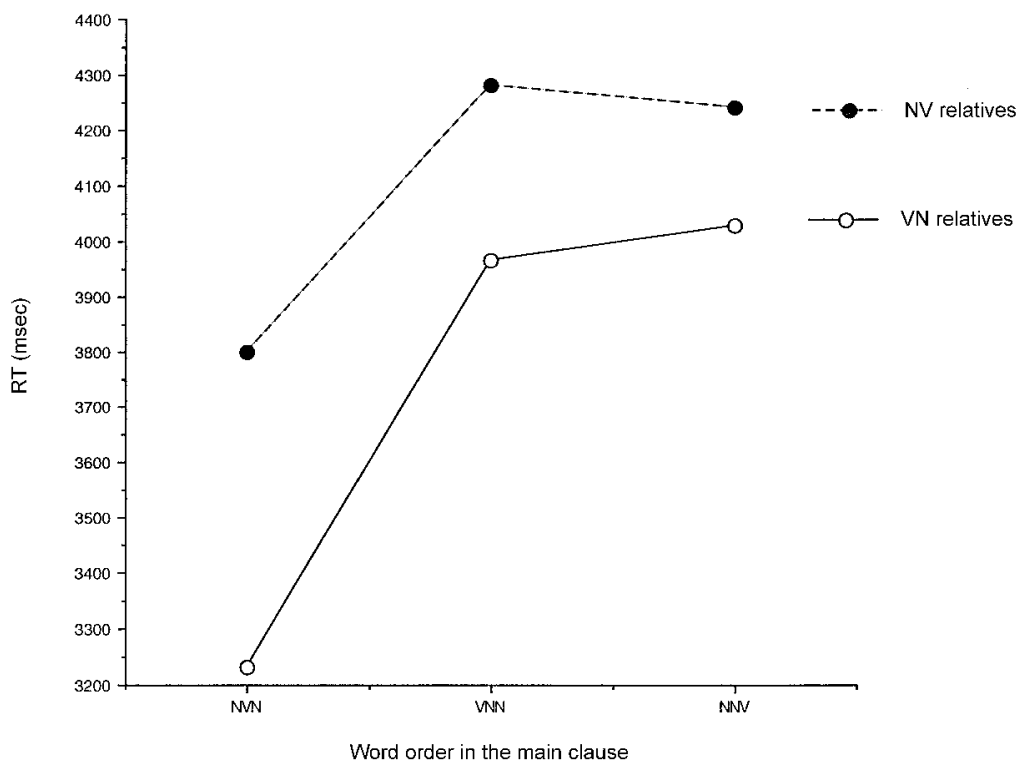

FIG. 9. Reaction times for the interpretation of the relative clause as a function of word order in both the main and relative clause (Experiment 3c). 
for early placement) and structural difficulty (especially degree of embeddedness). Overall, a relative clause that occurs early in the sentence (modifying the first noun, mean $=3796 \mathrm{msec}$ ) can be interpreted sooner than a relative clause that occurs relatively late (modifying the second noun, mean $=4053 \mathrm{msec}$ ). However, in some sentence types, the "early bird" also produces a more thickly embedded sentence, a fact which cancels out any advantages that early placement might otherwise afford. This is evident in Fig. 10, which displays the only effect involving language in this analysis, a complex three-way interaction of language, main clause order and relative clause position. On NVN items, which are easy to process, early placement of the relative provides a substantial advantage in English, despite the fact that early placement also results in centre embedding (i.e. $\mathrm{N}(\mathrm{rel}) \mathrm{VN}$ is easier than $\mathrm{NVN}(\mathrm{rel})$ ). On VNN items, which are more difficult to process, early placement slows things down in both languages (but more so in English), presumably because early placement results in embedding $(\mathrm{VN}(\mathrm{rel}) \mathrm{N})$ but late placement does not (VNN(rel)). On NNV items, which are by far the hardest to interpret, early placement offers a substantial advantage (especially in English), and late placement offers a substantial disadvantage (again, especially in English). Presumably, this is the case because embedding occurs in NNV no matter where

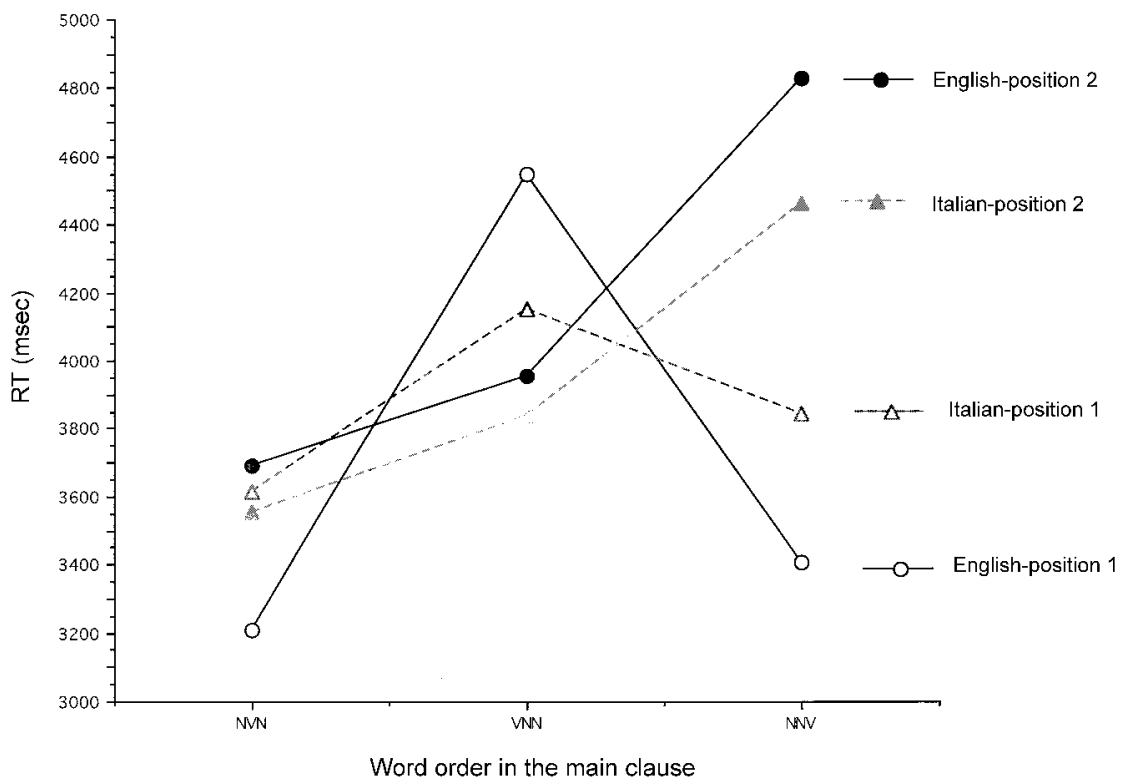

FIG. 10. Effects of main clause order and relative clause position on time to interpret the relative clause in English vs Italian (Experiment 3c). 
we place the relative $(\mathrm{N}(\mathrm{rel}) \mathrm{NV}$ and $\mathrm{NN}(\mathrm{rel}) \mathrm{V}$ are both centre-embedded structures), leaving the advantage of early placement to operate on its own. Both these factors have a larger effect in English.

Finally, the three-way interaction of main clause order, relative clause order and relative clause placement is illustrated in Fig. 11. This result (which does not interact with language) also reflects the interaction between early availability (a good thing) and embeddedness (a bad thing), as they relate to canonicity (i.e. $\mathrm{VN}$ relatives are easier than $\mathrm{NV}$ relatives).

To illustrate this last point, note that the easiest relative clauses among the 12 conditions illustrated in Fig. 11 are canonical VN forms that occur in a canonical NVN (in either position), and canonical VN forms that occur very early, right after the first noun in an NNV (resulting in sentences like "The secretary that shot the cowboy the policeman saw"). Although this last structure is non-canonical and heavily embedded at the level of the main clause, it may be easy when subjects have to interpret the relative, because they can stop paying attention to the rest of the sentence after they have processed a well-formed opening fragment (i.e. "The secretary that shot the cowboy ...").

In the same vein, the hardest relative clauses among the 12 conditions in Fig. 11 are those that involve lethal combinations of non-canonical relative

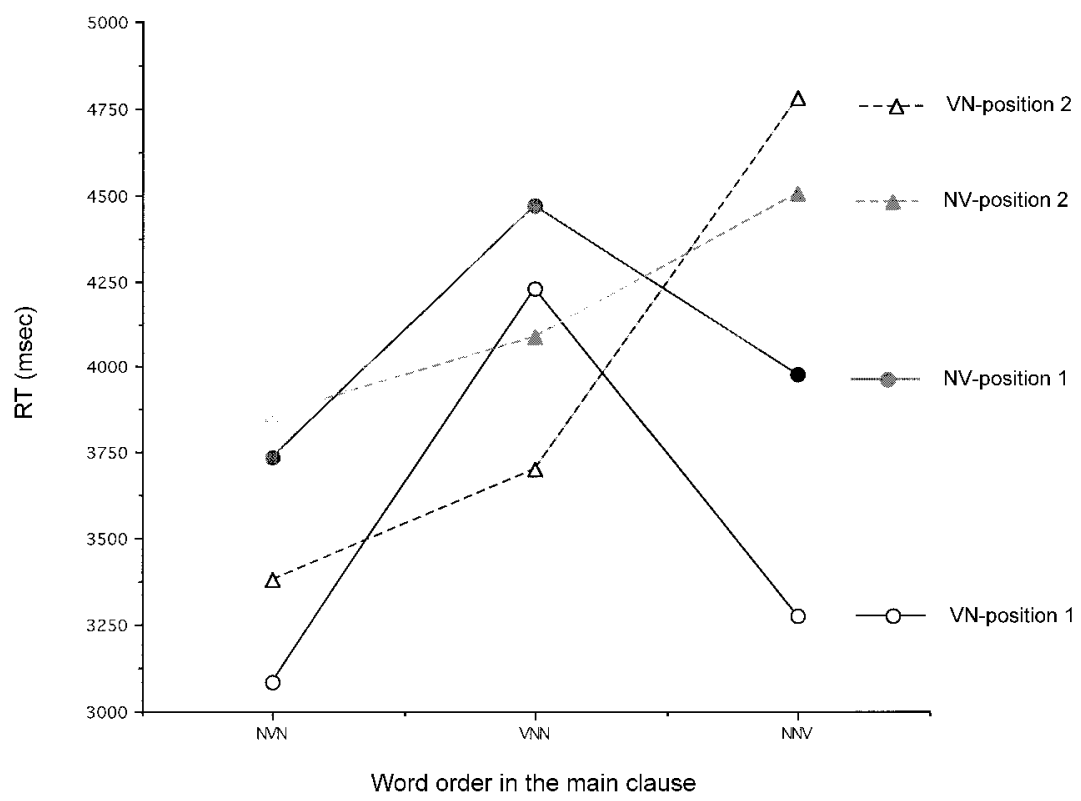

FG. 11. Reaction times for the interpretation of the relative clause as a function of main clause order, relative clause order and relative clause position (Experiment $3 \mathrm{c}$ ). 
clause order $(\mathrm{NV})$ in a non-canonical matrix $(\mathrm{NNV}$ or $\mathrm{VNN})$, with thick centre embedding (e.g. the three worst are $\mathrm{NN}(\mathrm{VN}) \mathrm{V}, \mathrm{NN}(\mathrm{NV}) \mathrm{V}$ and $\mathrm{VN}(\mathrm{NV}) \mathrm{V}$, in that order). In other words, horrible sentences take a long time to interpret, in both languages, although the price appears to be more severe in English.

\section{Summary of Experiment 3}

Reaction time findings in Experiment 3 are intricate, but they boil down to the interaction of some relatively straightforward principles: (1) reaction times are faster for canonical word order types, in both the main clause and the relative clause; (2) centre embeddings take longer to interpret; and (3) interpretation of the relative clause is faster (all other things being equal) when that clause is encountered early in the sentence. These factors operate in both languages, but they exact a great reaction time cost in English, leading to the speculation that embedding costs may be higher in a language that relies heavily on word order information (see Hawkins, 1994, for an extensive discussion of processing costs and linguistic typology).

This brings us to our final comparison, an on-line version of Experiment 2 , investigating the effects of variations in subject-verb agreement at both levels of the sentence, in relation to relative clause order and relative clause placement. In this experiment (as in Experiment 2), order in the main clause is held constant, in the canonical NVN. Again, we expect to find larger effects of agreement in Italian, and larger effects of relative clause order and relative clause placement in English, in both agent assignment (noun choice) and reaction times.

\section{EXPERIMENT 4: SUBJECT-VERB AGREEMENT VARIATIONS}

Subjects. The subjects for this experiment were 23 American and 23 Italian college students, meeting all the criteria outlined earlier. None of these subjects had participated in Experiments 1, 2 or 3. For analyses comparing Experiments 2 and 4, the last two of the 25 subjects in Experiment 2 were dropped, to equalise sample size.

Procedure. The stimuli were identical to those used in Experiment 2. The instructions, test procedures and scoring criteria were identical to those used in Experiment 3.

Scoring. Trials on which subjects failed to respond within the 5-sec time window were removed from the analysis, with mean agent assignment scores and mean reaction times based on the remaining trials within each 
cell. A total of $0.27 \%$ of all trials for English subjects and $0.64 \%$ of all trials for Italian subjects were removed owing to non-response.

\section{Results and Discussion (see Appendices 4 and 5 for statistical details)}

Before exploring the reaction time results obtained in this experiment, we began by examining the results for agent choice, to determine whether the results obtained off-line in Experiment 2 replicate when subjects are placed under time pressure. All of the analyses described for Experiment 2 were repeated using experiment ( $2 v s 4)$ as a between-subjects factor (see Appendix 4). The results were identical for Experiments $2 \mathrm{a}$ and $4 \mathrm{a}$, and for Experiments $2 \mathrm{~b}$ and $4 \mathrm{~b}$ (i.e. there were no main effects of interactions involving the factor "experiment"). Results for the third part of the experiment (interpretation of the relative clause, Experiment 2c vs Experiment 4c) were also similar in direction and magnitude, although there were a few small effects involving experiment as a factor. All of these effects were significant in Italian, but not in English. Examination of cell means led us to the culprit: The worst cell occurs in the Italian on-line condition, where an NV clause (non-canonical) occupies first position (maximal embedding), with ambiguous relative clause agreement (so that Italians cannot rely on their favourite cue). Italians are driven to random performance in this cell ( $50.4 \%$ object-relative interpretations, compared with $75 \%$ object-relative interpretations in the equivalent cell off-line). Interestingly, English subjects reach an object-relative interpretation $93.5 \%$ of the time in the same on-line cell. Hence the processing costs experienced by English and Italian speakers diverge in this particular condition, suggesting that English listeners are resistant (because they are not trying to use agreement information) while Italians are vulnerable (because they are trying very hard to use agreement information under the worst possible conditions). In all other respects, the off-line and on-line versions yield comparable results for agent choice. Therefore, in the interests of parsimony, we will restrict our discussion of Experiment 4 to reaction time findings.

Experiment 4a: Agreement in Simple Sentences. The main aim of this sub-experiment was to determine whether cross-linguistic differences in the use of subject-verb agreement are also reflected in reaction times, for simple sentences in the visual modality. Reaction times for the 15 sentences in this sub-experiment were analysed in a $2 \times 3$ design, with language treated as a between-subjects factor and agreement as a withinsubjects factor (see Appendix 5 for details). The main effect of language was large and reliable, reflecting much faster RTs in English (mean = 
$1416 \mathrm{msec})$ than Italian $($ mean $=2170 \mathrm{msec})$. Note also that the overall mean RTs in this experiment $(1793 \mathrm{msec})$ are $761 \mathrm{msec}$ faster than the mean RTs observed for simple sentences under the word order variations manipulated in Experiment 3a (2440 msec). Both these findings are due to the fact that all sentences in this section are in the canonical NVN order, a situation that leads to substantially faster reaction times overall, but especially in English. The main effect of agreement did not reach significance by the $P<0.01$ standard, nor did we find the expected interaction between language and agreement. This contrasts with other experiments in our laboratories, in which Italians were faster than English subjects with converging agreement (i.e. agreement with the first noun on NVN) and slower with competing agreement (i.e. agreement with the second noun on NVN). As we shall see below, the predicted interaction does appear in main clauses modified by a relative (Experiment $4 \mathrm{~b}$ ).

To summarise the results for simple sentences, Italians show much stronger effects of agreement variation than their English counterparts in off-line and on-line agent choice. Contrary to our expectations, this interaction does not show up in reaction times. However, the RT data do show that English listeners are much faster overall to interpret these canonical NVN strings.

Experiment 4b: Interpretation of the Main Clause. The main aim of this sub-experiment was to uncover cross-linguistic differences in the RT profiles associated with differential use of subject-verb agreement within the main clause in complex sentences. The materials and design were identical to those in Experiment $2 \mathrm{~b}$ with 180 complex items in which the criminal verb is located in the main clause. This RT analysis yielded a large number of significant effects (see Appendix 5), including a significant fourway interaction of language with agreement, order and position within the relative clause.

The main effect of language reflects much faster reaction times in English $($ mean $=2444 \mathrm{msec})$ than Italian $($ mean $=3433 \mathrm{msec})$. Bearing in mind that all the main clauses in Experiment $4 \mathrm{~b}$ are in the canonical NVN order, this result reflects the basic findings for agent choice described earlier. That is, English listeners apply their SVO strategies across the board, despite the various manipulations that we have imposed, while Italians vacillate between SVO and OVS in interaction with other factors. As a result, English listeners are much more efficient in this part of the study, while Italians pay a price for their willingness to accept OVS interpretations.

The interaction between language and main clause agreement confirms our prediction that Italians are influenced more by a competition between main clause order and main clause agreement. For Italians, reaction times 
averaged $3157 \mathrm{msec}$ with first-noun agreement, $3087 \mathrm{msec}$ for ambiguous items and $4056 \mathrm{msec}$ for competition items (which are usually interpreted as a non-canonical OVS). For Americans, reaction times averaged 2361 msec with first-noun agreement, $2394 \mathrm{msec}$ for ambiguous items and 2576 msec for competition items (which are interpreted as a canonical SVO). The competition effect proved to be reliable in both languages when the data were analysed separately, so this language difference is simply a matter of degree.

All of the remaining main effects and interactions can be understood in terms of variations in processing load. Factors that slow down interpretation of the matrix clause include non-canonical agreement (with the second noun in the main clause; with the embedded noun in the relative clause), non-canonical word order (NV in the relative) and centre embedding (when the relative modifies the first noun in these NVN strings). These factors apply to some extent in both language groups. However, our findings for agent assignment clearly indicate that English speakers "trust" word order and Italian speakers "trust" agreement at both levels of the sentence. Hence, in this sub-experiment, we should expect bigger effects of relative clause order and embedding on reaction times in English, and bigger effects of main and relative clause agreement on reaction times in Italian. The results are largely in line with these predictions.

First, the main effect of relative clause order reflects faster RTs in the presence of a canonical VN relative (mean $=2849 \mathrm{msec}$ ) and slower RTs when the main clause is modified by a non-canonical NV relative (mean = $3028 \mathrm{msec}$ ). This variable does not interact with language, which means that both language groups slow down in the presence of an NV relative (note that the main effect of relative clause order just misses significance, $P<0.012$, when English is analysed separately; see Appendix 5).

Second, the main effect of relative clause position reflects faster RTs when the relative modifies the second noun (no centre embedding, mean = $2384 \mathrm{msec}$ ) and slower RTs when the relative modifies the first noun (with centre embedding, mean $=3492 \mathrm{msec}$ ). This embedding effect also holds in both languages, but the significant language $\times$ position interaction tells us that the cost of centre embedding is greater in English (mean RT in position $1=3179 \mathrm{msec} v s 1710 \mathrm{msec}$ in position 2) than Italian (mean RT in position $1=3807 \mathrm{msec} v s 3059 \mathrm{msec}$ in position 2).

Finally, there was no significant main effect for relative clause agreement, but this variable did interact with a number of other factors, including language. For the sake of economy, we will restrict our discussion to the four-way interaction, because this higher-order interaction subsumes most of the other effects. As before, we began our exploration of this complex interaction by conducting separate analyses in English and Italian. 
Figure 12a illustrates the relationships among relative clause agreement, order and position in Italian. This three-way interaction was not reliable for Italians alone. Hence the pattern for Italians in Fig. 12a actually reflects three separate results: (1) a main effect of relative clause order (with slower RTs in the presence of an NV relative), (2) a large main effect of position (with slower RTs with the RT in position 1), and (3) a two-way interaction of relative clause agreement and relative clause order. The interaction (see Fig. 12a) shows that the advantage of canonical order (VN) within the relative clause is wiped out in Italian when agreement runs in the opposite direction.

The corresponding results for English are illustrated in Fig. 12b. A separate analysis of the English data shows that the full three-way interaction is statistically reliable. The most obvious feature in Fig. 12b is the massive effect of embedding, with RTs in centre-embedded sentences that are more than $1000 \mathrm{msec}$ longer than RTs on sentences that end in a relative clause. It is also clear from Fig. 12b that the RT difference between "easy" VN and "hard" NV relatives is relatively small, which means that the distracting effect of a non-canonical relative is not as troublesome for the English group in this part of the experiment. For our English subjects, the most troublesome cell in the design contains items with the relative clause in the first position (embedded sentences), in NV order (a non-canonical form), where the verb inside the relative clause agrees with the head noun (in direct competition with an NV interpretation). Hence English listeners are not entirely immune to the distracting effects of relative clause agreement, but such effects are only observed under the worst possible conditions of embedding and non-canonicity.

To summarise the results for interpretation of the main clause, there are larger effects of word order and embedding in English, and larger effects of agreement in Italian, in accord with the predictions of the Competition Model. However, processing costs are in the same general direction for both groups (i.e. slower RTs with centre embedding, and in the presence of a non-canonical relative clause).

Experiment 4c: Interpretation of the Relative Clause. The main aim of this final sub-experiment was to assess cross-linguistic differences in the processing costs associated with variations in agreement inside the relative clause. In particular, we predicted that agreement effects within the relative would be greater for Italians. The materials and design were identical to those in Experiment 2c. Once again, there were a large number of significant effects (see Appendix 5), including a four-way interaction of language with all three relative clause factors (agreement and order within the clause, and position of the clause within the sentence). 


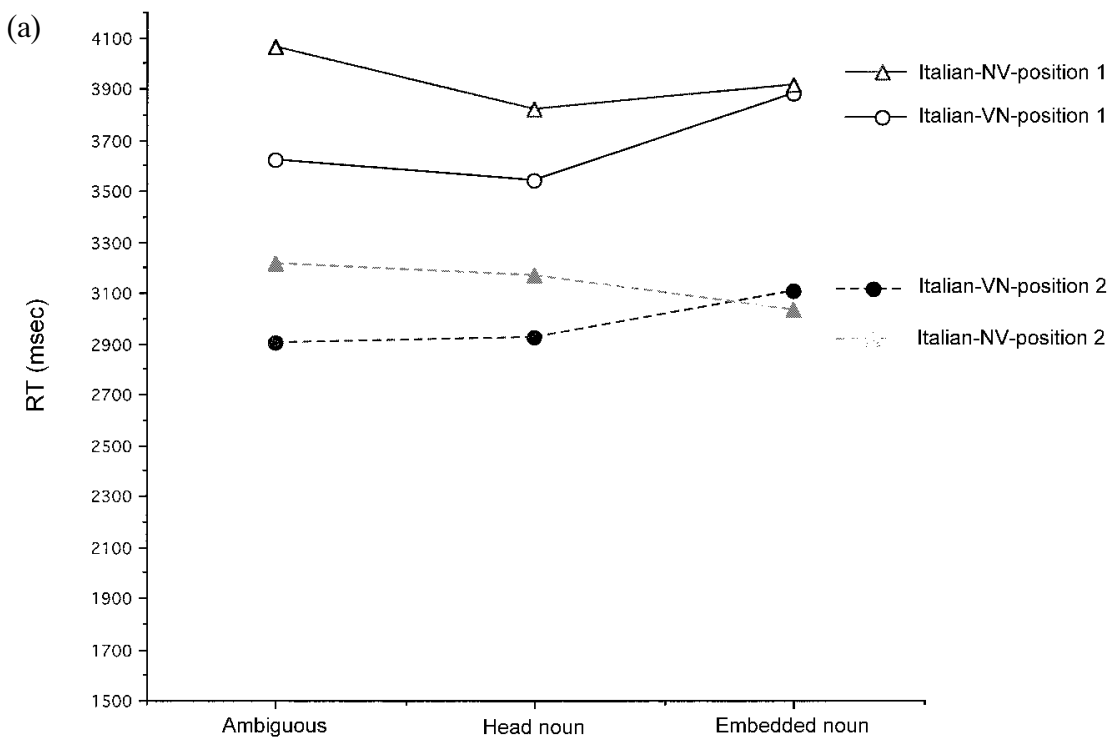

Agreement conditions in the relative clause

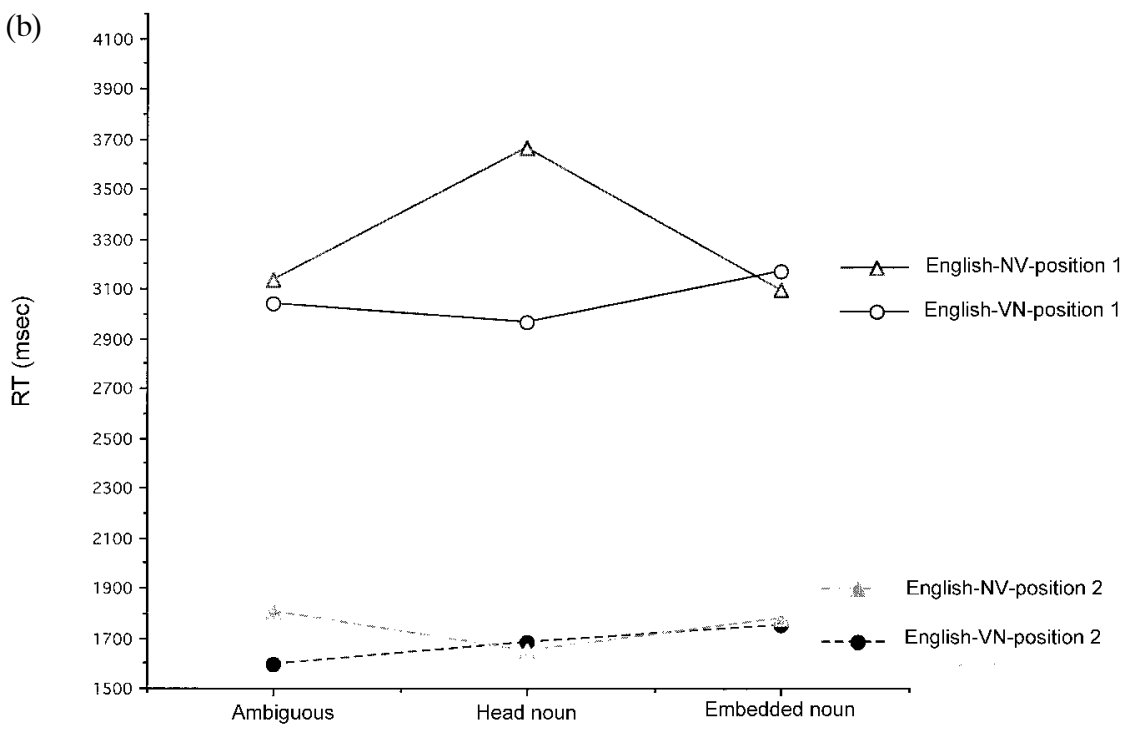

Agreement conditions in the relative clause

FIG.12. (a) Effects of relative clause agreement, order and position on time to interpret the main clause, in Italian only (Experiment 4b). (b) Effects of relative clause agreement, order and position on time to interpret the main clause, in English only (Experiment $4 \mathrm{~b}$ ). 
All of these effects reflect a combination of cross-linguistic differences (i.e. relative clause agreement is more important in Italian; relative clause order and position are more important in English) and variations in processing load that apply in both languages. The processing facts (which may be universal) are the same ones described earlier: (1) reaction times are slower in the presence of non-canonical forms (when the verb in the main clause agrees with the second noun; when either word order or agreement in the relative clause favour an object-relative interpretation), and (2) reaction times are slower in the presence of embedding, although (3) early placement of the relative can provide an RT advantage (an "early bird" strategy).

First, the main effect of agreement within the main clause was in line with our predictions, reflecting slower performance with agreement on the second noun (a competition between default SVO and agreement-induced OVS). As expected, separate analyses for each language showed that this effect only reached significance in Italian. In other words, because English speakers do not care very much about agreement, a violation of agreement in the main clause does not delay their interpretations of the relative. In contrast, the same effect increases processing load for Italians, and slows them down across the board.

Second, the main effect of agreement within the relative clause reflects slower performance when agreement supports an object-relative interpretation $($ mean $=3289 \mathrm{msec})$, compared with roughly similar RTs for morphologically ambiguous relatives (mean $=3051 \mathrm{msec})$ and for items in which agreement fosters a subject-relative interpretation (mean $=3079$ msec). In accord with our predictions, separate analyses within each language showed that this agreement manipulation does not reach significance in English but is highly reliable in Italian. Hence it is the Italian group that is most affected by agreement manipulations, at both levels of the sentence.

Third, the main effect of relative clause order reflects faster performance on canonical VN clauses $($ mean $=2940 \mathrm{msec})$ and slower performance on non-canonical NV clauses $($ mean $=3339 \mathrm{msec})$. In this case, there was no two-way interaction with language, indicating that relative clause order is important for both groups However, there was a reliable three-way interaction of language with relative clause agreement and relative clause order, illustrated in Fig. 13. Several aspects of our results are evident in Fig. 13, including the much greater reaction time advantage for English subjects, who rely faithfully on word order and pay little attention to agreement. It is also clear from Fig. 13 that the three-way interaction is coming from Italian, where there is a crossover interaction between order and agreement within the relative clause: Italians are slower on NV clauses when agreement is ambiguous or when agreement and NV order are in 


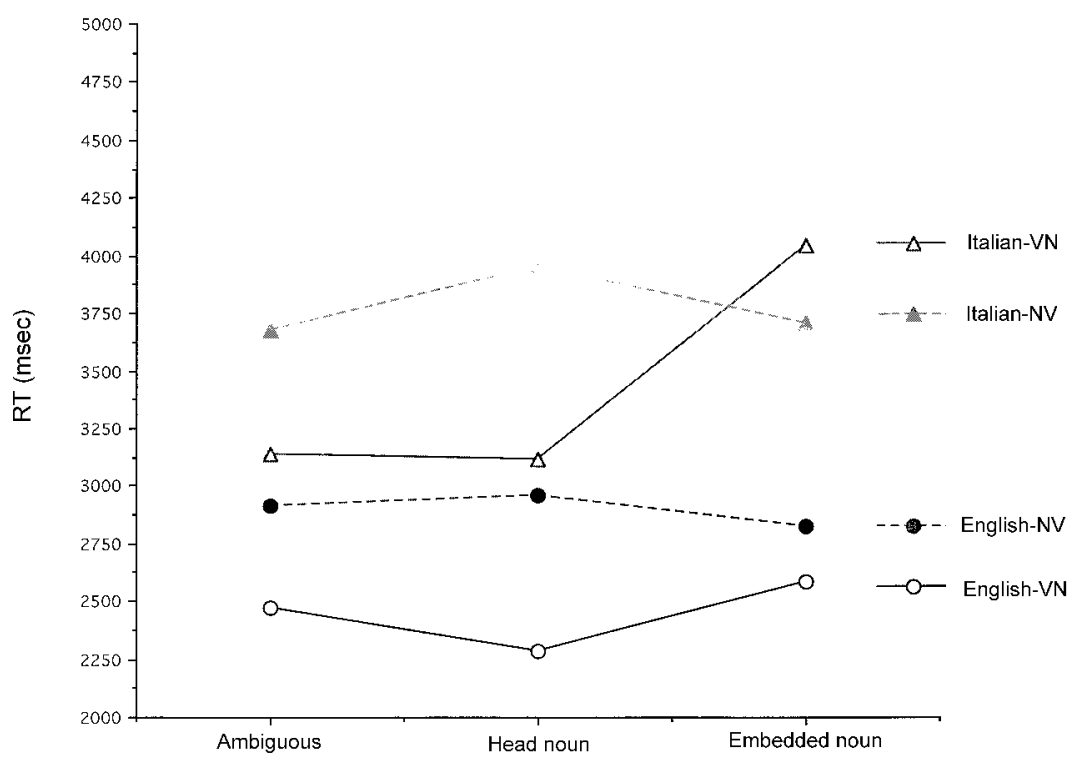

Agreement conditions in the relative clause

FIG. 13. Effects of order and agreement within the relative clause on time to interpret the relative clause (Experiment $4 \mathrm{c}$ ).

competition, but they are faster on NV clauses when agreement and order converge. These reaction time results mirror our findings for agent choice, both on-line and off-line, and they are also similar to the subtle three-way interactions observed for interpretation of the main clause in Experiment 4b.

The remaining effects all involve relative clause position, and it is here that we begin to see some language-specific processing costs in English. The main effect of position is the same in both languages, an "early bird" effect with faster RTs for early relatives (mean = $2974 \mathrm{msec}$ ) and slower RTs for later relatives $($ mean $=3305 \mathrm{msec}$ ). However, the advantages of early placement may be counteracted in some cases by the costs associated with centre embedding. In fact, separate analyses of English and Italian reveal that all interactions of relative clause position with the other factors are coming from the English group. This includes the interaction between relative clause order and position, and the three-way interaction of position, order and agreement within the relative clause. The three-way interaction for English alone is presented in Fig. 14, which illustrates several interesting facts. First, there is no difference between canonical VN and non-canonical NV when these clauses occur late in the sentence (i.e. 


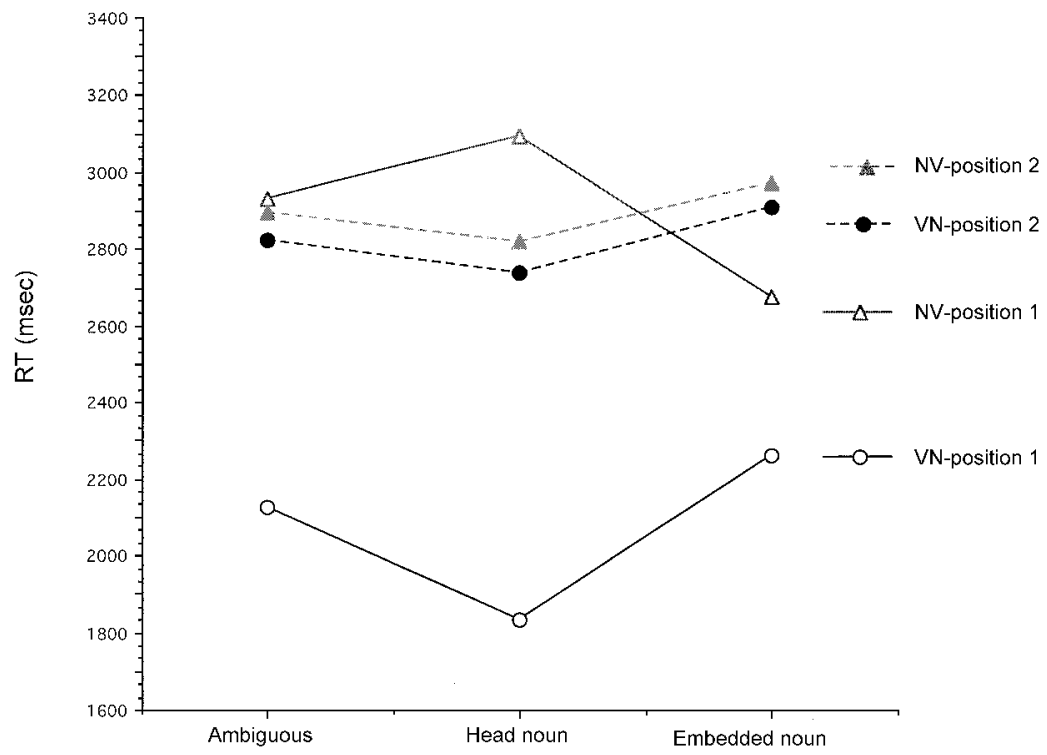

Agreement conditions in the relative clause

FIG. 14. Effects of order, agreement and position of the relative clause on time to interpret the relative clause, for English only (Experiment 4c).

with no centre embedding), nor can we find any evidence that relative clause agreement makes a difference when the clause occurs in sentencefinal position, outside of the matrix sentence. Second, English speakers respond very quickly and efficiently to "early bird" relatives that modify the first noun, but only if the relative is a canonical VN. In this case, we also find some facilitation from converging agreement. These findings make sense if we remember that these items lend themselves to early interpretation, with processing interrupted half way through the sentence (e.g. "The secretary that shoots the cowboys ..."). This is less true for NV clauses in first position, particularly when there is competition between order and agreement (e.g. "The secretaries that the cowboy shoot ..."). In these cases, the advantage of early placement is apparently overcome by the disadvantages of embedding and non-canonical form.

In general, the results for this section support the view that word order is the major factor influencing interpretation of the relative clause in English, although English reaction times are also affected by degree of embedding and the presence of non-canonical forms. Subject-verb agreement is the major determinant of relative clause interpretation in Italian, although non-canonical word order does exact a cost. 


\section{Summary of Experiment 4}

We have uncovered some extraordinarily complex effects in this experiment, but the major findings are in the directions predicted by the Competition Model. English subjects show a marked RT advantage overall (due to the canonical order of the matrix clause), but they also display greater effects of centre embedding, interacting with canonical form in the relative clause. Italian subjects show pronounced effects of subject-verb agreement at both levels of the sentence, evidenced in large delays when canonical word order and subject-verb agreement are in competition, in either the main clause or the relative clause. At the same time, Italians show relatively few effects of embedding in their reaction time data. Hence our results suggest that the costs associated with centre embedding are greater in languages that rely heavily on word order, and lighter (although still present) in languages that rely more on morphological information. We may speculate that the costs of centre embedding are lower in a richly inflected language because listeners can sometimes rely on "local" solutions to agent interpretation, while English listeners have to keep the topology of the sentence in mind in order to reach an interpretation.

\section{CONCLUSIONS}

The main aim in this study was to determine whether (and to what extent) the cross-linguistic differences in sentence interpretation that we have observed with simple sentences also generalise to complex sentences with an embedded clause. After this long journey, we can say with some confidence that the answer is "yes". Native speakers of English rely primarily on word order information, in simple sentences, in the main clause of sentences with a relative clause, and inside the relative clause itself. This tendency is evident in their sentence interpretations both online and off-line, and in the speed with which solutions are reached in the on-line versions of each experiment. Native speakers of Italian rely primarily on subject-verb agreement, in both the main clause and the relative clause, despite variations in word order, canonicity and degree of centre embedding. This tendency is also evident on-line and off-line, in agent choice and in reaction times.

In both languages, these tendencies do break down under some structural conditions. For example, English speakers fall towards chance when they have to interpret horrific centre embeddings like "The secretary the cowboy that the policeman shoots sees". Italian speakers also fall towards chance when they are forced to interpret non-canonical centreembedded structures with no morphological contrasts. Hence there are 
clear limits on processing strategies that characterise and differentiate performance in these languages.

Between the two extremes of language-specific performance and random behaviour, the reaction time results of Experiments 3 and 4 provide some insights into universal processing costs and their languagespecific instantiations. For both language groups, processing is more difficult (and reaction times are slowed accordingly) in the presence of non-canonical structures, at either level of the sentence. This includes noncanonical word orders (NNV and VNN in the main clause; NV in the relative) and forms of agreement that compete with canonical word order (agreement on the second noun in an NVN main clause; agreement with the embedded noun in a VN relative or with the head noun in an NV relative). In both languages, centre embedding can slow the interpretation of a main clause, although the magnitude of this embedding cost depends on other factors. Early placement can hasten the interpretation of a relative clause (i.e. the "early bird" effect), but this factor also interacts with other structural facts (especially the interplay between early placement and centre embedding).

Although these processing costs are observed in both languages (and might be put forward as candidates for "processing universals"), there are also robust cross-linguistic differences in the price that must be paid. English listeners pay a larger price for centre embedding, leading us to speculate that resistance to centre embedding may be a natural by-product of heavy reliance on word order (i.e. the "dark side" of a word order language). Italians are less affected by centre embedding, at least within the variations that we have attempted here, a fact that may result from the application of "local" solutions in a language that relies heavily on agreement morphology. However, Italians do pay a significant cost in processing time when agreement must compete with a strong (albeit nondeterministic) word order bias. Agreement does "win" in such situations, but only after a measurable delay. We must assume that such dilemmas rarely come up in everyday life for Italian speakers, due to the convergence of lexical, prosodic and contextual information that usually applies when non-canonical word orders are used. But when competition does occur, and other favourite sources of information are not around to settle the fight, Italians pay a greater cost than English speakers (who really don't care very much about any source of information other than word order).

Of course, more research is needed to achieve a more complete understanding of cross-linguistic similarities and differences in the time course of language processing. However, the cross-language differences that we have uncovered here regarding preferred interpretations of complex sentences and their associated processing costs have interesting 
implications not only for future psycholinguistic research, but for typological and diachronic linguistics. Theorists like Hawkins (1994) and Givón (1995) have speculated about the role of processing constraints on historical language change, and on the class of languages that can be processed in real time. Although these hypotheses are well grounded in linguistic data, and appear to have considerable face validity (based on introspection about what is "hard" or "easy" in one's native language), cross-linguistic studies of on-line sentence processing may provide a more solid grounding to speculations about the factors that force historical language change. The results presented here suggest that the costs associated with centre embedding and the costs involved in processing of non-canonical word order types are both greater in a language that relies heavily on word order. Conversely, the costs associated with pockets of morphological ambiguity and real or illusive morphological competition may be greater in a language that permits extensive word order variation. Hence we may find that different languages have different "breaking points" when the communicative process is placed under pressure, in the lifetime of an individual and perhaps in the lifetime of the language itself.

Manuscript received April 1998 Revised manuscript received September 1998

\section{REFERENCES}

Bates, E., Friederici, A., \& Wulfeck, B. (1987). Comprehension in aphasia: A crosslinguistic study. Brain and Language, 32, 19-67.

Bates, E., MacWhinney, B., Caselli, C.M., Devescovi, A., Natale, F., \& Venza, V. (1984). A cross-linguistic study of the development of sentence interpretation strategies. Child Development, 55, 341-354.

Bates, E., McNew, S., MacWhinney, B., Devescovi, A., \& Smith, S. (1982). Functional constraints on sentence processing: A cross-linguistic study. Cognition, 11, 245-299.

Bates, E., Wulfeck, B., \& MacWhinney, B (1991). Crosslinguistic research in aphasia: An overview. Brain and Language, 41, 123-148.

Bazzanella, C. (1994). Le facce del parlare. Florence: La Nuova Italia.

Benincà, P. (1993). Sintassi. In A.A. Sobrero (Ed.), Introduzione all'italiano contemporaneo: Le Strutture (Introduction to contemporary Italian: Structures) (pp. 41-100). Florence: La Nuova Italia.

Brunswik, E. (1956). Perception and the representative design of psychology experiments. Berkeley, CA: University of California Press.

Caplan, D., \& Hildebrandt, N. (1988). Disorders of syntactic comprehension. Cambridge, MA: MIT Press.

Cohen, J., MacWhinney, B., Flatt, M., \& Provost, J. (1993). PsyScope: A new graphic interactive environment for designing psychology experiments. Behavior Research Methods, Instrument \& Computers, 25, 257-271. 
Devescovi, A. (1992). Sentence comprehension in Italian children from 2 to 9 years of age. Paper presented at the International Colloquium on Cross-Linguistic Research on the Processing, Acquisition and Disorders of Language, Université René Descartes, Paris, December.

Devescovi, A., Bates, E., D’Amico, S. Hernandez, A., Marangolo, P., Pizzamiglio, L., \& Razzano, C. (1997). Grammaticality judgments in patients with and without expressive agrammatism. Aphasiology, 11, 543-579.

Devescovi, A., D'Amico, S., Smith, S., Mimica, I., \& Bates, E. (1998). The development of sentence comprehension in Italian and Serbo-Croatian: Local versus distributed cues. In D. Hillert (Ed.), Sentence processing: A cross-linguistic perspective (pp. 345-377). San Diego, CA: Academic Press.

Devescovi, P. (1986). Ordine delle parole in italiano: Aspetti linguistici e psicologici (Word order in Italian: Linguistic and psychological aspects). Doctoral dissertation, Università degli studi di Roma "La Sapienza".

Duranti, A., \& Ochs, E. (1979). Left-dislocation in Italian conversation. In T. Givón (Ed.), Syntax and semantics: Discourse and syntax (pp. 377-416). New York: Academic Press.

Gibson, E. (1992). On the adequacy of the competition model (Review of The crosslinguistic study of sentence processing). Language, $68,812-830$.

Givón, T. (1995). Functionalism and grammar. Philadelphia, PA: J. Benjamins.

Gregory, R.L. (1966). Eye and brain: The psychology of seeing. London: Weidenfeld \& Nicolson.

Hawkins, J. (1994). A performance theory of order and constituency. New York: Cambridge University Press.

Hernandez, A., Bates, E., \& Avila, L. (1994). On-line sentence interpretation in SpanishEnglish bilinguals: What does it mean to be "in between"? Applied Psycholinguistics, 15, 417-446.

Kail, M. (1989). Cue validity, cue cost, and processing types in French sentence comprehension. In B. MacWhinney \& E. Bates (Eds), The crosslinguistic study of language processing (pp. 77-117). New York: Cambridge University Press.

Kilborn, K. (1987). Sentence processing in a second language: Seeking a performance definition of fluency. $\mathrm{PhD}$ dissertation, University of California, San Diego, CA.

Kilborn, K., \& Ito, T. (1989). Sentence processing strategies in adult bilinguals. In B. MacWhinney \& E. Bates (Eds), The crosslinguistic study of sentence processing (pp. 257291). New York: Cambridge University Press.

Kimball, J. (1973). Seven principles of surface structure parsing in natural language. Cognition, 2, 15-47.

Li, P., Bates, E., \& MacWhinney, B. (1993). Processing a language without inflections: A reaction time study of sentence interpretation in Chinese. Journal of Memory and Language, 32, 169-192.

Liu, H., Bates, E., \& Li, P. (1992). Sentence interpretation in bilingual speakers of English and Chinese. Applied Psycholinguistics, 13, 451-484.

MacWhinney, B., \& Bates, E. (Eds) (1989). The crosslinguistic study of sentence processing. New York: Cambridge University Press.

MacWhinney, B., Bates, E., \& Kliegl, R. (1984). Cue validity and sentence interpretation in English, German and Italian. Journal of Verbal Learning and Verbal Behaviour, 23, 127150.

MacWhinney, B., \& Pléh, C. (1988). The processing of restrictive relative clauses in Hungarian. Cognition, 29, 95-141.

Massaro, D. (1987). Speech perception by ear and eye: A paradigm for psychological inquiry. Hillsdale, NJ: Lawrence Erlbaum Associates Inc. 
Sheldon, A. (1974). On the role of parallel function in the acquisition of relative clauses in English. Journal of Verbal Learning and Verbal Behavior, 13, 272-281.

Simone, R. (1990). Fondamenti di linguistica (Foundations of linguistics). Bari: La Terza.

Simone, R. (1993). Stabilita' e instabilita' nei caratteri originali dell'italiano [Stability and instability in original characters in Italian]. In A.A. Sobrero (Ed.), Introduzione all'italiano contemporaneo: Le Strutture [Introduction to contemporary Italian: Structures] (pp. 247290). Florence: La Nuova Italia.

Smith, S., \& Bates, E. (1987). Accessibility of case and gender contrasts for agent-object assignment in Broca's aphasics and fluent anomics. Brain and Language, 30, 8-32.

Smith, S., \& Mimica, I. (1984). Agrammatism in a case-inflected language: Comprehension of agent-object relations. Brain and Language, 21, 274-290.

Wulfeck, B., Bates, E., \& Capasso, R. (1991). A crosslinguistic study of grammaticality judgments in Broca's aphasia. Brain and Language, 41, 311-336.

\section{APPENDIX 1}

Italian/English relative clause experiment: Nouns and verbs used

\begin{tabular}{llll}
\hline Italian & English & Italian & English \\
\hline N1S (animals) & $\begin{array}{l}\text { N1S (animals) } \\
\text { the dog }\end{array}$ & $\begin{array}{l}\text { N1P (animals) } \\
\text { i cani }\end{array}$ & $\begin{array}{l}\text { N1P (animals) } \\
\text { the dogs }\end{array}$ \\
il cane & the skunk & le puzzole & the skunks \\
la puzzola & the mole & le talpe & the moles \\
la talpa & the horse & i cavalli & the horses \\
il cavallo & the kangaroo & i canguri & the kangaroos \\
il canguro & the cat & i gatti & the cats \\
il gatto & the elephant & gli elefanti & the elephants \\
l'elefante & the lion & i leoni & the lions \\
il leone & the tiger & le tigri & the tigers \\
la tigre & the cow & le mucche & the cows \\
la mucca & the seal & le foche & the seals \\
la foca & the giraffe & le giraffe & the giraffes \\
la giraffa & N2S (humans) & $\mathbf{N 2 P}$ (humans) & N2P (humans) \\
& the carpenter & i falegnami & the carpenters \\
N2S (humans) & the teacher & le maestre & the teachers \\
il falegname & the secretary & le segretarie & the secretaries \\
la maestra & the doctor & i dottori & the doctors \\
la segretaria & the hairdresser & i parrucchieri & the hairdressers \\
il dottore & the professor & i professori & the professors \\
il parrucchiere & the waitress & le cameriere & the waitresses \\
il professore & the cook & i cuochi & the cooks \\
la cameriera & the farmer & i contadini & the farmers \\
il cuoco & the ballerina & le ballerine & the ballerinas \\
il contadino & &
\end{tabular}


Italian/English relative clause experiment: Nouns and verbs used

\begin{tabular}{|c|c|c|c|}
\hline Italian & English & Italian & English \\
\hline il soldato & the soldier & i soldati & the soldiers \\
\hline il pagliaccio & the clown & i pagliacci & the clowns \\
\hline il dentista & the dentist & i dentisti & the dentists \\
\hline V1S & V1S & V1P & V1P \\
\hline picchia & strikes & picchiano & strike \\
\hline morde & bites & mordono & bite \\
\hline tira & shoots & tirano & shoot \\
\hline colpisce & hits & colpiscono & hit \\
\hline rompe & breaks & rompono & break \\
\hline graffia & scratches & graffiano & scratch \\
\hline uccide & murders & uccidino & murder \\
\hline pizzica & pinches & pizzicano & pinch \\
\hline brucia & burns & bruciano & burn \\
\hline suffoca & suffocates & soffocano & suffocate \\
\hline spinge & pushes & spingono & push \\
\hline strozza & strangles & strozzano & strangle \\
\hline distrugge & destroys & distruggono & destroy \\
\hline ammazza & kills & ammazzano & kill \\
\hline bastona & beats & bastonano & beat \\
\hline V2S & V2S & V2P & V2P \\
\hline vede & sees & vedono & see \\
\hline aspetta & expects & aspettano & expect \\
\hline sente & hears & sentono & hear \\
\hline ascolta & listens to & ascoltano & listen to \\
\hline guarda & watches & guardano & watch \\
\hline chiama & calls & chiamano & call \\
\hline cerca & seeks & cercano & seek \\
\hline segue & follows & seguono & follow \\
\hline osserva & observes & osservano & observe \\
\hline
\end{tabular}

\section{APPENDIX 2}

Sample English Sentences for Experiments 1-4 ${ }^{a, b}$

\section{Experiments 1 and 3: Word order variations}

1a/3a: Simple sentences only

NVN: The secretary shoots the cook

NNV: The secretary the cook shoots

VNN: Shoots the secretary the cook

\section{1b/3b: Main clause interpretation}

NVN: The secretary that sees the doctor shoots the cook (rel. pos. 1, VN) The secretary that the doctor sees shoots the cook (rel. pos. 1, NV) 
The secretary shoots the cook that sees the doctor The secretary shoots the cook that the doctor sees

NNV: The secretary that sees the doctor the cook shoots The secretary that the doctor sees the cook shoots The secretary the cook that sees the doctor shoots The secretary the cook that the doctor sees shoots

VNN: Shoots the secretary that sees the doctor the cook Shoots the secretary that the doctor sees the cook Shoots the secretary the doctor that sees the cook Shoots the secretary the doctor that the cook sees

\section{$1 c / 3 c$ : Relative clause interpretation}

NVN: The secretary that shoots the doctor sees the cook The secretary that the doctor shoots sees the cook The secretary sees the cook that shoots the doctor The secretary sees the cook that the doctor shoots

NNV: The secretary that shoots the doctor the cook sees The secretary that the doctor shoots the cook sees The secretary the cook that shoots the doctor sees The secretary the cook that the doctor shoots sees

VNN: Sees the secretary that shoots the doctor the cook Sees the secretary that the doctor shoots the cook Sees the secretary the doctor that shoots the cook Sees the secretary the doctor that the cook shoots

\section{Experiments 2 \& 4: Agreement Variations ${ }^{3}$}

\section{2a/4a: Simple sentences only}

Ag0: The secretary shoots the doctor

Ag1: The secretary shoots the doctors

Ag3: The secretary shoot the doctors

\section{2b/4b: Main clause interpretation}

Ag0: The secretary that sees the doctor shoots the cook main The secretary that the doctor sees shoots the cook The secretary that sees the doctors shoots the cook The secretary that the doctors sees shoots the cook The secretary that see the doctors shoots the cook The secretary that the doctors see shoots the cook

The secretary shoots the cook that sees the doctor The secretary shoots the cook that the doctor sees The secretary shoots the cook that sees the doctors The secretary shoots the cook that the doctors sees The secretary shoots the cook that see the doctors The secretary shoots the cook that the doctors sees

Ag1: The secretary that sees the doctor shoots the cooks main The secretary that the doctor sees shoots the cook The secretary that sees the doctors shoots the cooks (rel. pos. 2,NV) (rel. pos. $1, \mathrm{VN}$ )

(rel. pos. $1, \mathrm{VN}$ ) (rel. pos. $1, \mathrm{NV}$ ) (rel. pos. 2, VN) (rel. pos. 2,NV)

(rel. pos. $1, \mathrm{VN}$ ) (rel. pos. 1,NV) (rel. pos. 2, VN) (rel. pos. 1, NV)

(rel. pos. 1, VN) (rel. pos. 1, NV) (rel. pos. 2, VN) (rel. pos. 2,NV)

(rel. pos. 1, VN) (rel. pos. 1,NV) (rel. pos. 2, VN) (rel. pos. 2,NV) (rel. pos. 1, VN) (rel. pos. 1,NV) (rel. pos. 2, VN) (rel. pos. 2,NV) (rel. pos. 1, VN, Ag0 rel) (rel. pos. 1, NV, Ag0 rel) (rel. pos. 1, VN, Ag1 rel) (rel. pos. 1, NV, Ag1 rel) (rel. pos. 1, VN, Ag2 rel) (rel. pos. 1, NV, Ag2 rel) (rel. pos. 2, VN, Ag0 rel) (rel. pos. 2, NV, Ag0 rel) (rel. pos. 2, VN, Ag1 rel) (rel. pos. 2, NV, Ag1 rel) (rel. pos. 2, VN, Ag2 rel) (rel. pos. 2, NV, Ag2 rel) (rel. pos. 1, VN, Ag0 rel) (rel. pos. 1, NV, Ag0 rel) (rel. pos. 1, VN, Ag1 rel) 
The secretary that the doctors sees shoots the cooks The secretary that see the doctors shoots the cooks The secretary that the doctors see shoots the cooks

The secretary shoots the cooks that sees the doctor The secretary shoots the cooks that the doctor sees The secretary shoots the cooks that sees the doctors The secretary shoots the cooks that the doctors sees The secretary shoots the cooks that see the doctors The secretary shoots the cooks that the doctors see

Ag2: The secretary that sees the doctor shoot the cooks main The secretary that the doctor sees shoot the cooks The secretary that sees the doctors shoot the cooks The secretary that the doctors sees shoot the cooks The secretary that see the doctors shoot the cooks The secretary that the doctors see shoot the cooks

The secretary shoot the cooks that sees the doctor The secretary shoot the cooks that the doctor sees The secretary shoot the cooks that sees the doctors The secretary shoot the cooks that the doctors sees The secretary shoot the cooks that see the doctors The secretary shoot the cooks that the doctors see (rel. pos. 1, NV, Ag1 rel) (rel. pos. 1, VN, Ag2 rel) (rel. pos. 1, NV, Ag2 rel)

(rel. pos. 2, VN, Ag0 rel) (rel. pos. 2, NV, Ag0 rel) (rel. pos. 2, VN, Ag1 rel) (rel. pos. 2, NV, Ag1 rel) (rel. pos. 2, VN, Ag2 rel) (rel. pos. 2, NV, Ag2 rel)

(rel. pos. 1, VN, Ag0 rel) (rel. pos. 1, NV, Ag0 rel) (rel. pos. 1, VN, Ag1 rel) (rel. pos. 1, NV, Ag1 rel) (rel. pos. 1, VN, Ag2 rel) (rel. pos. 1, NV, Ag2 rel)

(rel. pos. 2, VN, Ag0 rel) (rel. pos. 2, NV, $\mathrm{Ag} 0 \mathrm{rel}$ ) (rel. pos. 2, VN, Ag1 rel) (rel. pos. 2, NV, Ag1 rel) (rel. pos. 2, VN, Ag2 rel) (rel. pos. 2, NV, Ag2 rel)

\section{2c/4c: Relative clause interpretation}

Ag0: The secretary that shoots the doctor sees the cook main The secretary that the doctor shoots sees the cook The secretary that shoots the doctors sees the cook The secretary that the doctors shoots sees the cook The secretary that shoot the doctors sees the cook The secretary that the doctors shoot sees the cook

The secretary sees the cook that shoots the doctor The secretary sees the cook that the doctor shoots The secretary sees the cook that shoots the doctors The secretary sees the cook that the doctors shoots The secretary sees the cook that shoot the doctors The secretary sees the cook that the doctors shoot

Ag1: The secretary that shoots the doctor sees the cooks main The secretary that the doctor shoots sees the cooks The secretary that shoots the doctors sees the cooks The secretary that the doctors shoots sees the cooks The secretary that shoot the doctors sees the cooks The secretary that the doctors shoot sees the cooks

The secretary sees the cooks that shoots the doctor The secretary sees the cooks that the doctor shoots The secretary sees the cooks that shoots the doctors The secretary sees the cooks that the doctors shoots The secretary sees the cooks that shoot the doctors The secretary sees the cooks that the doctors shoots

(rel. pos. 1, VN, $\mathrm{Ag} 0 \mathrm{rel}$ ) (rel. pos. 1, NV, Ag0 rel) (rel. pos. 1, VN, Ag1 rel) (rel. pos. 1, NV, Ag1 rel) (rel. pos. $1, \mathrm{VN}, \mathrm{Ag} 2$ rel) (rel. pos. 1, NV, Ag2 rel)

(rel. pos. 2, VN, $\mathrm{Ag} 0 \mathrm{rel}$ ) (rel. pos. 2, NV, Ag0 rel) (rel. pos. 2, VN, Ag1 rel) (rel. pos. 2, NV, Ag1 rel) (rel. pos. 2, VN, Ag2 rel) (rel. pos. 2, NV, Ag2 rel)

(rel. pos. 1, VN, Ag0 rel) (rel. pos. $1, \mathrm{NV}, \mathrm{Ag} 0 \mathrm{rel}$ ) (rel. pos. 1, VN, Ag1 rel) (rel. pos. 1, NV, Ag1 rel) (rel. pos. 1, VN, Ag2 rel) (rel. pos. 1, NV, Ag2 rel)

(rel. pos. 2, VN, Ag0 rel) (rel. pos. 2, NV, Ag0 rel) (rel. pos. 2, VN, Ag1 rel) (rel. pos. 2, NV, Ag1 rel) (rel. pos. 2, VN, Ag2 rel) (rel. pos. 2, NV, Ag2 rel) 


\section{BATES ET AL.}

Ag2: The secretary that shoots the doctor see the cooks main The secretary that the doctor shoots see the cooks The secretary that shoots the doctors see the cooks The secretary that the doctors shoots see the cooks The secretary that shoot the doctors see the cooks The secretary that the doctors shoot see the cooks

The secretary see the cooks that shoots the doctor The secretary see the cooks that the doctor shoots The secretary see the cooks that shoots the doctors The secretary see the cooks that the doctors shoots The secretary see the cooks that shoot the doctors The secretary see the cooks that the doctors shoot

(rel. pos. 1, VN, Ag0 rel) (rel. pos. 1, NV, Ag0 rel) (rel. pos. 1, VN, Ag1 rel) (rel. pos. 1, NV, Ag1 rel) (rel. pos. 1, VN, Ag2 rel) (rel. pos. 1, NV, Ag2 rel)

(rel. pos. 2, VN, Ag0 rel) (rel. pos. 2, NV, Ag0 rel) (rel. pos. 2, VN, Ag1 rel) (rel. pos. 2, NV, Ag1 rel) (rel. pos. 2, $\mathrm{VN}, \mathrm{Ag} 2$ rel) (rel. pos. 2, NV, Ag2 rel)

\footnotetext{
${ }^{a}$ For the sake of economy, only English examples are listed; Italian items are direct translations, with verbs in the present indicative (e.g. "shoots" = spara; "shoot" = sparano).

${ }^{b}$ The same lexical items are used in all examples to facilitate comparison; actual stimuli contain five different randomised assignments of lexical items to conditions (see Table 1).

${ }^{c}$ These examples are restricted to cases in which the first noun is singular and the second noun is plural on all items with an agreement contrast; in the full set of stimuli, plural $v s$ singular nouns and verbs are counterbalanced across all agreement conditions.

Abbreviation: rel. pos. $=$ relative position .
} 


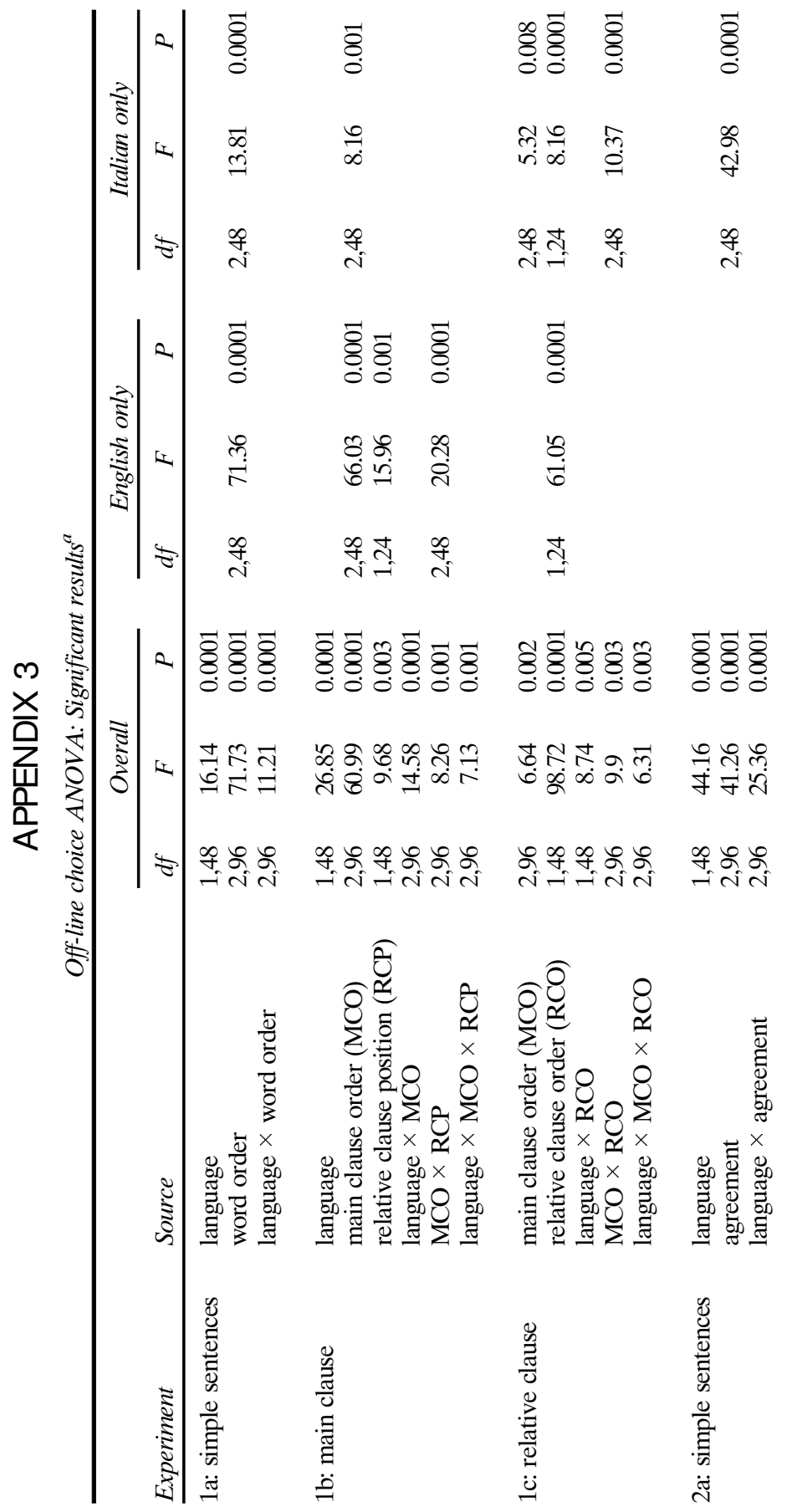




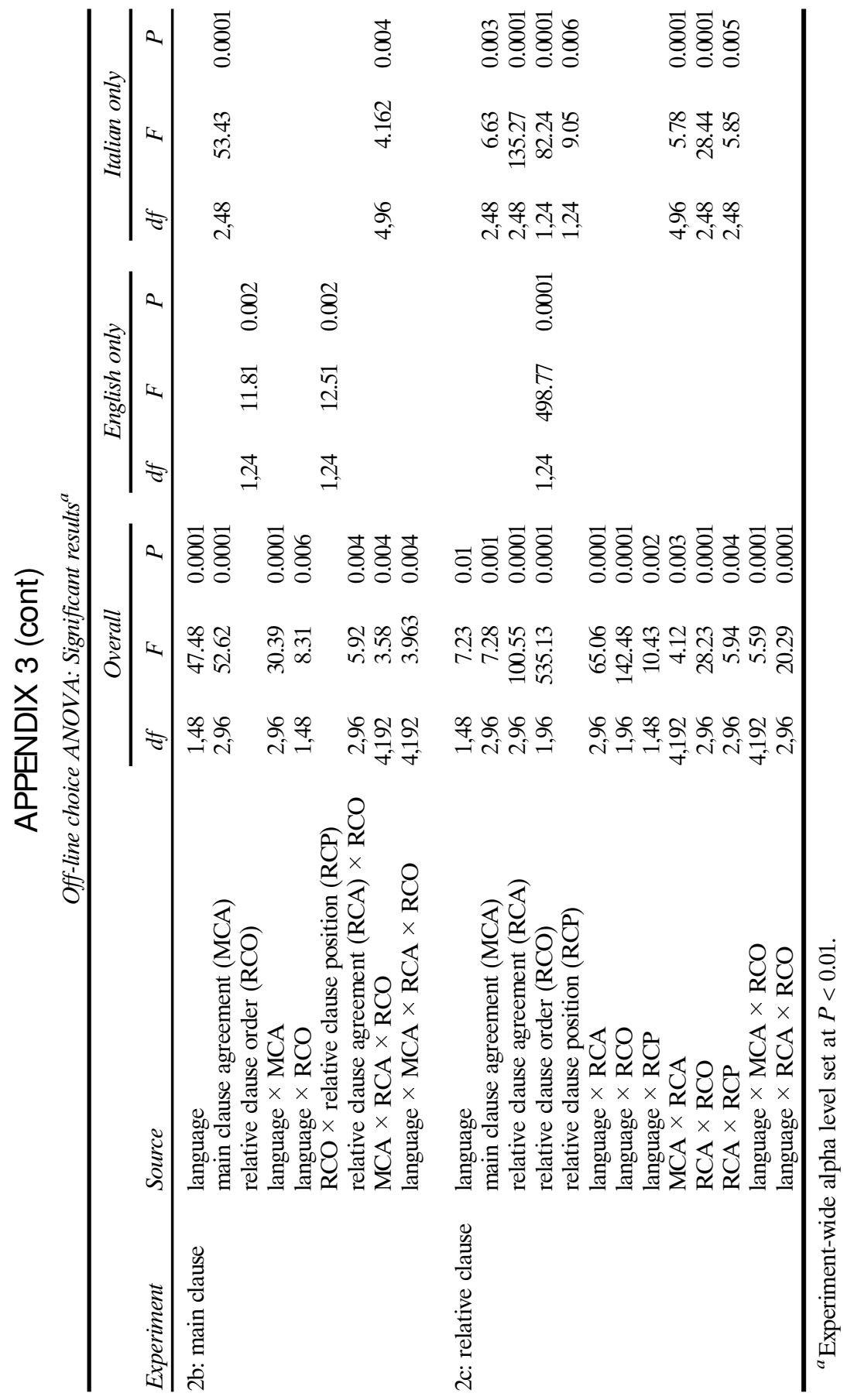




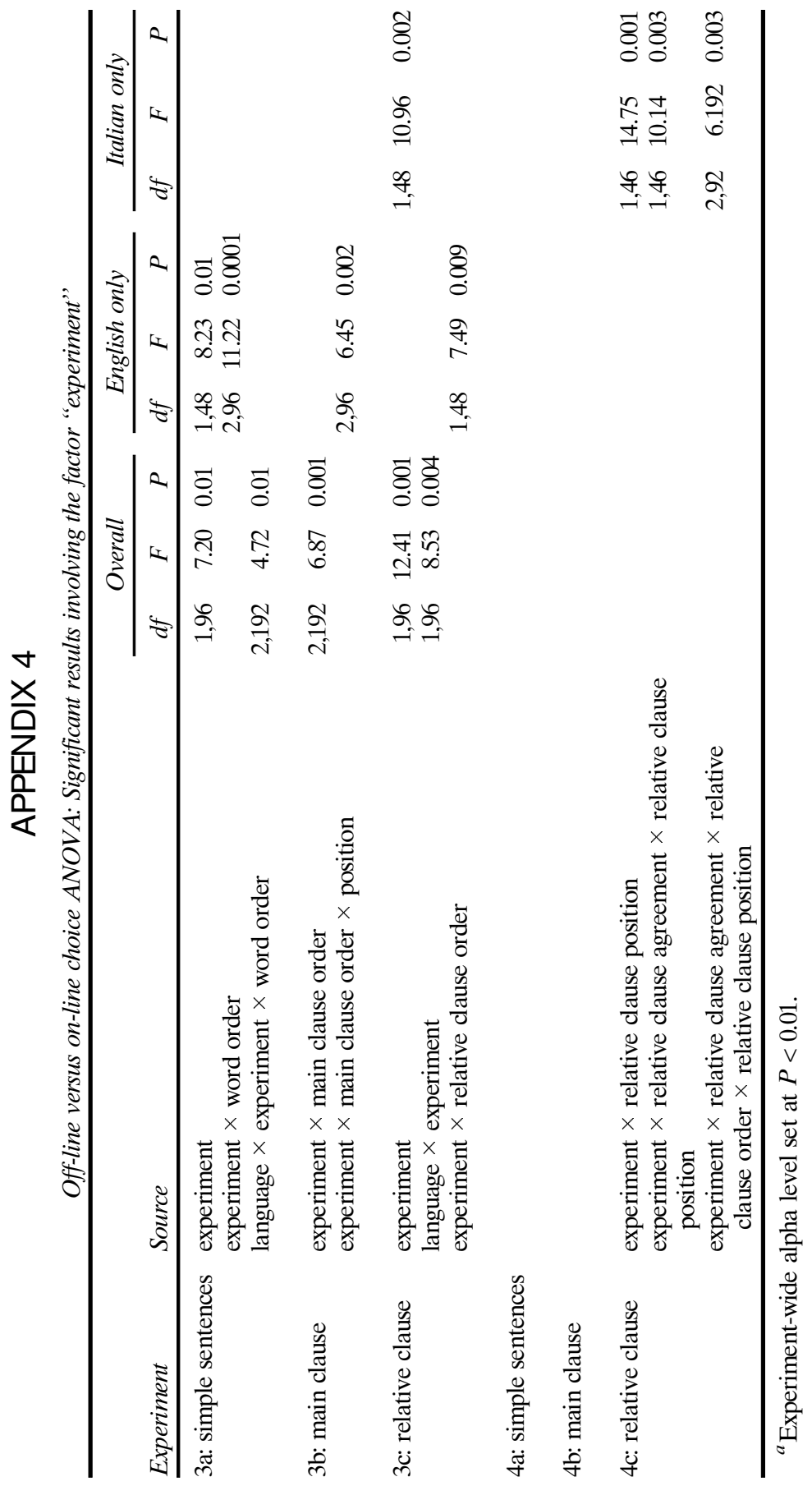




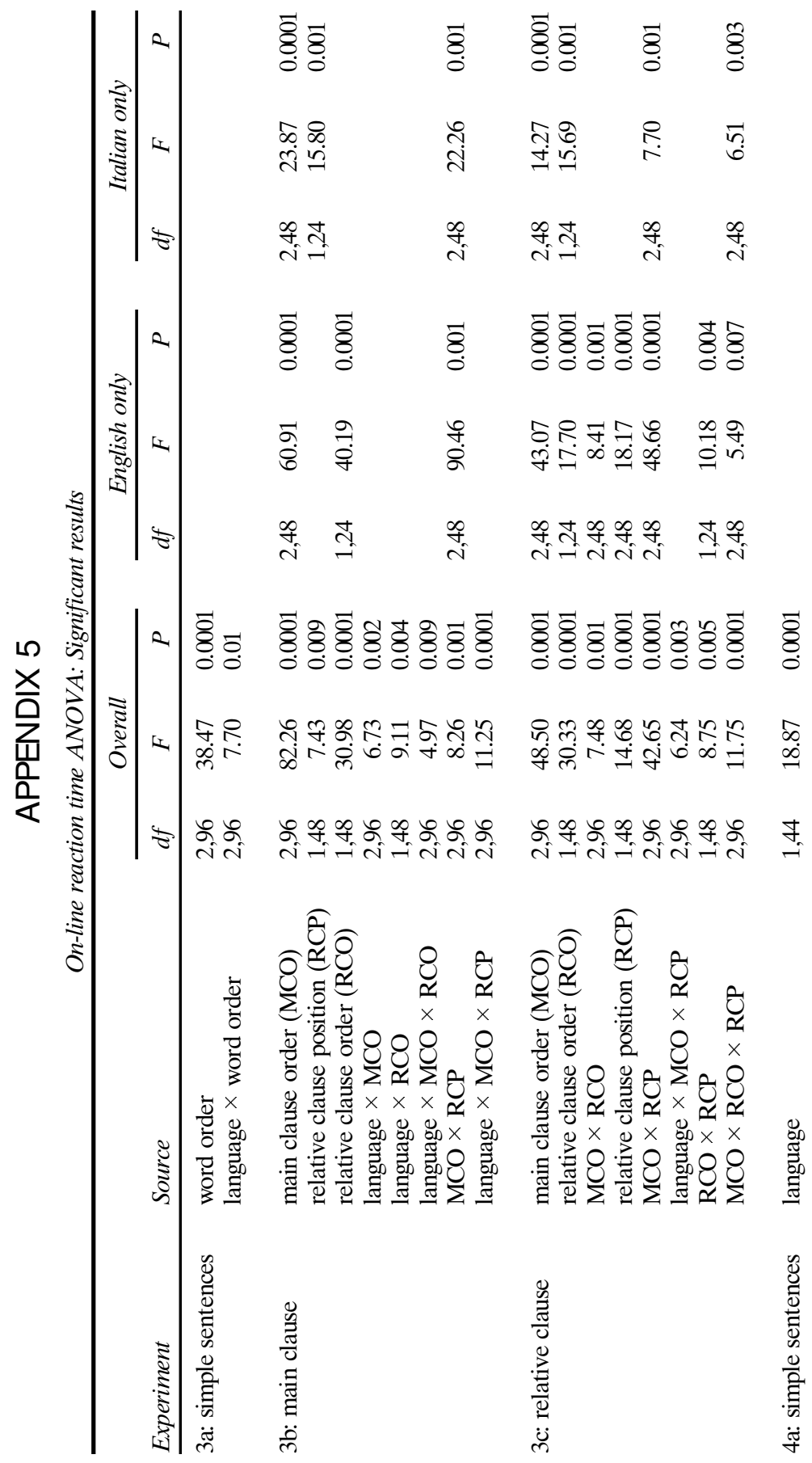




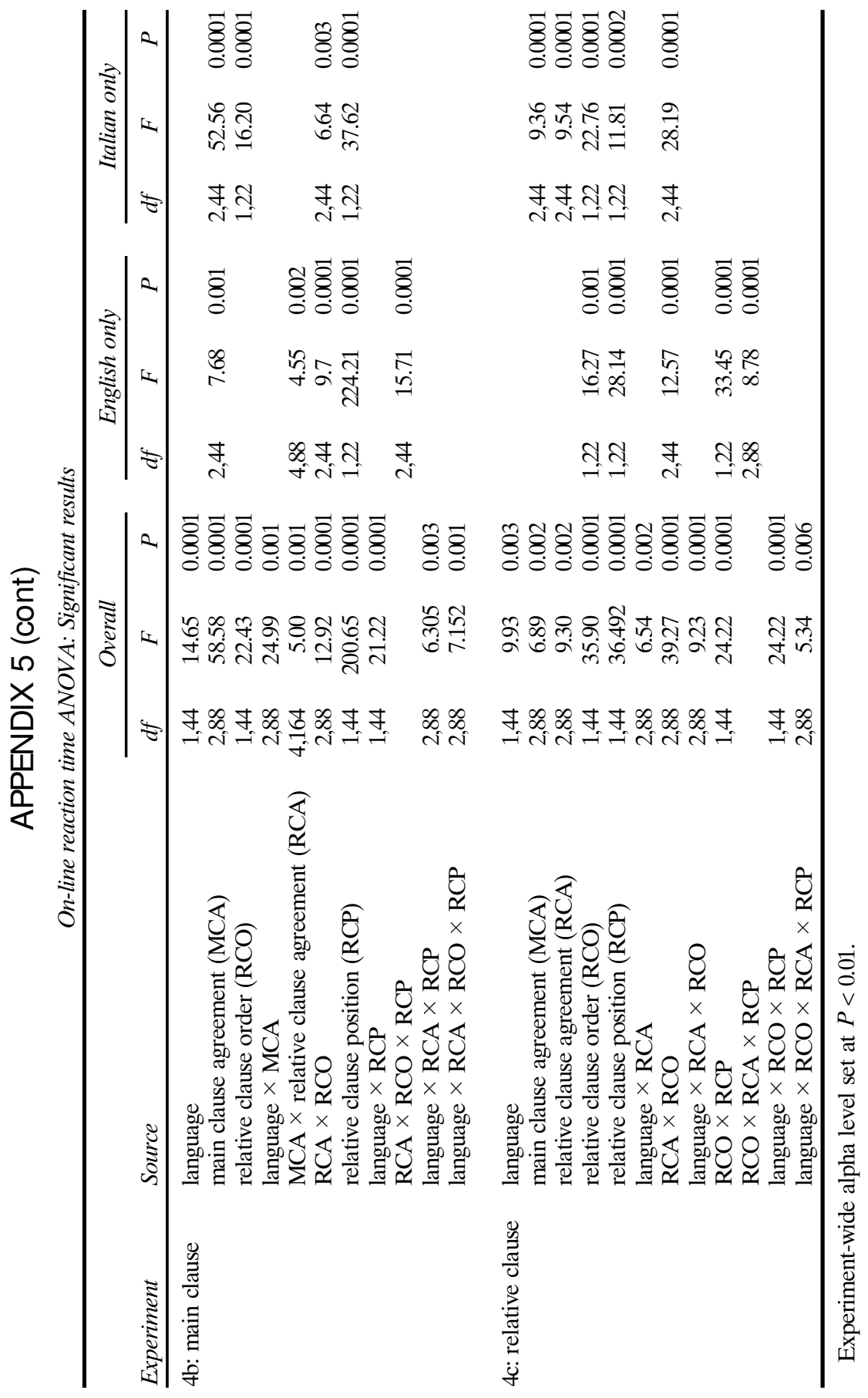

